\title{
Socially responsible investment portfolios: does the optimization process matter?
}

\section{Article}

\section{Accepted Version}

Creative Commons: Attribution-Noncommercial-No Derivative Works 4.0

Oikonomou, I., Platanakis, E. and Sutcliffe, C. (2018) Socially responsible investment portfolios: does the optimization process matter? The British Accounting Review, 50 (4). pp. 379-401. ISSN 0890-8389 doi: https://doi.org/10.1016/j.bar.2017.10.003 Available at https://centaur.reading.ac.uk/73426/

It is advisable to refer to the publisher's version if you intend to cite from the work. See Guidance on citing.

Published version at: http://linkinghub.elsevier.com/retrieve/pii/S0890838917300719

To link to this article DOI: http://dx.doi.org/10.1016/j.bar.2017.10.003

Publisher: Elsevier

All outputs in CentAUR are protected by Intellectual Property Rights law, including copyright law. Copyright and IPR is retained by the creators or other copyright holders. Terms and conditions for use of this material are defined in the End User Agreement.

\section{www.reading.ac.uk/centaur}

\section{CentAUR}

Central Archive at the University of Reading 
Reading's research outputs online 


\title{
Socially Responsible Investment Portfolios: Does the Optimization Process Matter?
}

\author{
Ioannis Oikonomou \\ ICMA Centre, Henley Business School, University of Reading, UK
}

\section{Emmanouil Platanakis}

University of Bath, School of Management, UK

\section{Charles Sutcliffe}

ICMA Centre, Henley Business School, University of Reading, UK

\section{Dr. Ioannis Oikonomou*}

ICMA Centre, Henley Business School, University of Reading, PO Box 242

Whiteknights, Reading, RG6 6BA, UK.

E-mail: 1.oikonomou@,icmacentre.ac.uk

\section{Dr. Emmanouil Platanakis}

University of Bath, School of Management

Claverton Down, 8 West, Bath, BA2 7AY, UK

E-mail: E.Platanakis@bath.ac.uk

\section{Professor Charles Sutcliffe}

ICMA Centre, Henley Business School, University of Reading, PO Box 242

Whiteknights, Reading, RG6 6BA, UK.

E-mail: c.sutcliffe@icmacentre.ac.uk

*Corresponding author. We would like to thank Professors Nikolaos Tessaromatis Sotiris Tsolacos, Chris Brooks, Michael Clements, Nathan Joseph and participants of the Financial Management Association (FMA) European Conference 2016, Spring 2016 Conference of the Multinational Finance Society (FMS), British Accounting \& Finance Association (BAFA) 2016 Annual Conference and 5th International Conference of the Financial Engineering and Banking Society (FEBS) and two anonymous reviewers for their comments on previous versions of this paper. All remaining errors are the sole responsibility of the authors. 


\begin{abstract}
This study investigates the impact of the choice of optimization technique when constructing Socially Responsible Investment (SRI) portfolios. Corporate Social Performance (CSP) scores are price sensitive information that is subject to considerable estimation risk. Therefore, uncertainty in the input parameters is greater for SRI portfolios than conventional portfolios, and this affects the selection of the appropriate optimization method. We form SRI portfolios based on six different approaches and compare their performance along the dimensions of risk, risk-return trade-off, diversification and stability. Our results for SRI portfolios contradict those of the conventional portfolio optimization literature. We find that the more "formal" optimization approaches (Black-Litterman, Markowitz and robust estimation) lead to SRI portfolios that are both less risky and have superior risk-return trade-offs than do more simplistic approaches; although they also have more unstable asset allocations and lower diversification. Our conclusions are robust to a series of tests, including the use of different estimation windows and stricter screening criteria.
\end{abstract}

Keywords: corporate social responsibility; CSR; CSP; SRI; sustainability; portfolio optimization JEL Classification: C61, G11, M14 


\section{Introduction}

Corporate Social Responsibility (CSR) and Corporate Social Performance (CSP) ${ }^{1}$ have become crucially important concepts in the modern business world. Broadly defined as "a management concept whereby companies integrate social and environmental concerns in their business operations and interactions with their stakeholders" ${ }^{\prime 2}$, it has gained traction over the past 20 years. A growing number of stakeholders have increased societal demands that corporations perform well financially, while operating in a responsible and ethical manner.

This trend is noticeable in the latest surveys. Grant Thornton's International Business Report ${ }^{3}$ in 2014 surveyed 2,500 firms in 34 countries and showed that more and more businesses are adopting socially and environmentally sustainable practices and initiatives. These range from charitable donations and active participation in local community causes to improving energy efficiency and applying more effective waste management. The majority of these firms cite client/consumer demand as one of the dominant driving forces behind their decision to move to more sustainable business formats. Similarly, the Nielsen Global Survey on Corporate Social Responsibility (2013) used a sample of 29,000 participants from 58 countries and found that at least half of global consumers are willing to "walk the talk" and pay a premium for goods and services produced by socially responsible firms.

In line with these developments, demand for CSP in financial markets, also known as Socially Responsible Investing (SRI) ${ }^{4}$, has also been growing rapidly. According to the Global Sustainable Investment Review 2012, which is a product of the collaboration of a variety of organizations and sustainable investment forums across the world, approximately US $\$ 13.6$ trillion of assets under professional management incorporate environmental, social or governance considerations into the investment selection process. This represents more than $20 \%$ of the total assets under professional management in the areas covered in the report, and includes positive and negative screening,

\footnotetext{
${ }^{1}$ The two terms have been used interchangeably in relevant empirical research. In this paper, we use CSP.

2 United Nations Industrial Development Organization, retrieved October 2014 from http://www.unido.org/en/what-we-do/trade/csr/what-is-csr.html

${ }^{3}$ For additional information, the interested reader is directed at http://www.grantthornton.co.uk/en/Media-Centre/News/2014/Global-survey-finds-good-CSR-makes-good-businesssense-British-businesses-reacting-to-stakeholders-demands/, retrieved October 2014.

${ }^{4}$ Also referred to as Environmental, Social, and Governance Investing, Sustainable Investing and Impact Investing, though there are some conceptual differences between these terms.
} 
shareholder activism strategies, norm-based screening, best-in-class approaches and other forms of SRI. While the criteria for an investment to be deemed socially responsible are not strict, it is undeniable that SRI is nowadays a large and expanding segment of the financial markets.

As a result, a significant amount of scholarly research has been dedicated to the investigation of the nature of the relationship between CSP and firm financial performance. Meta-studies focusing on this area (Margolis et al., 2009; Orlitzky et al., 2003) demonstrate both its depth and breadth. Using data from hundreds of relevant papers going as far back as 1972, these studies provide evidence of an overall positive link between the two concepts. At the portfolio level of analysis, comparing SRI funds and indices with "conventional" funds and indices with otherwise similar characteristics commonly points to statistically indistinguishable performance (Renneboog et al., 2008; Schroder, 2007; Statman, 2000; Statman, 2006), although there are indications of SRI outperformance in certain contexts (Derwall and Koedijk, 2009; Kempf and Osthoff, 2007).

Despite the size of this literature, a very small number of studies has investigated optimal ways to construct SRI portfolios, either in the sense of the screening criteria used to narrow the investment universe, or the optimization process employed to determine the asset proportions. Barnett and Salomon (2006) is one of the few papers that focuses on the effects of screening intensity in SRI funds, and provides evidence of a U-shaped relationship between the number of social/environmental screens used and fund performance. Similarly, there is only a handful of papers (Ballestero et al. 2012; Drut, 2012; Utz et al. 2014) which explore the portfolio optimization frameworks used in SRI. Although such studies contribute significantly to this underdeveloped part of the literature, they do not go far beyond the Markowitz (1952) mean-variance optimization framework. They simply extend it by adding SRI preferences as an additional constraint, or incorporate them in the objective function or investigate the change in the mean-variance efficient frontier when screening using sustainability criteria. Although Markowitz optimization is the basis for the vast majority of modern portfolio optimization methods, it suffers from significant estimation risk (Green and Hollofield, 1992; DeMiguel et al., 2009a), and this leads to solutions that are very sensitive to the inputs, and the generation of unstable and poorly diversified portfolios.

This omission of estimation risk is unfortunate as, compared to conventional portfolios, SRI portfolios are characterised by a greater level of uncertainty in their inputs. This is due to the inherent complexity in measuring CSP, and the largely discretionary nature of CSP reporting (Bernardi and Stark, forthcoming; Qiu et al, 2016). So, within the SRI framework it is important to consider alternative optimization techniques, and to investigate the extent to which they lead to 
the construction of substantially different portfolios in terms of risk, risk-return trade-off, diversification and the stability of the constituent assets.

We use the MSCI ESG STATS (formerly known as KLD) database and focus on the qualitative issue areas of highest importance (community relations, diversity in the workplace, treatment of employees, environmental issues, product safety and quality) as identified by the previous literature (Hillman and Keim, 2001; Oikonomou et al., 2012; Krüger, 2015) to narrow down the investment universe to a selection of CSP champions. These best performing social and environmental corporate actors are the most likely to be targeted by SRI funds for inclusion in their specialised portfolios. Hence, our study contributes to the literature by applying six different optimization methods $^{5}$ to this SRI-screened investment universe, and comparing their out-of-sample performance as captured by 14 different metrics indicative of various important portfolio characteristics. In this way our study is the first to answer the question of whether the portfolio optimization process matters in SRI, and to further contextualise this answer by indicating which methods tend to lead to better results.

More specifically, our results clearly indicate that more quantitatively sophisticated optimization techniques lead to the construction of portfolios with lower risk, higher risk-adjusted returns and greater cumulative wealth compared to the less formal methods. Although sophisticated techniques do not do well in terms of the diversification and intertemporal stability of their constituent assets, this does not create significant practical issues as their returns are still the highest, even after accounting for transaction costs. Comparatively, among all the optimization methods we compare and all the metrics we apply, the Black-Litterman approach tends to perform best, while naïve diversification $(1 / N)$ usually performs worst.

It should be noted that many previous studies of conventional assets, which are reviewed below in section 2 , have found that portfolios formed using naïve rules such as $1 / N$ outperform those formed using more sophisticated optimization techniques. Nevertheless, we find that this conclusion does not apply to SRI portfolios. SRI portfolios are formed from a sub-set of the shares available to those forming conventional portfolios, and so fewer diversification benefits may be available. However, our SRI portfolios contain 100 (or 80) firms, and previous empirical research has established that portfolios of this size reap almost all the benefits available from diversification

\footnotetext{
5 Although all of these techniques are frequently referenced as optimization methods, the broader term "portfolio construction" is more accurate in some cases. We follow the norm and hereafter refer to the entire set of alternative methods as optimization methods.
} 
across all listed shares, e.g. Elton and Gruber (1977) and Statman (1987). In addition, we are not comparing the performance of SRI and conventional portfolios, but rather the relative performance of different optimization methods when applied to SRI and conventional portfolios. Therefore any reduction in diversification benefits for SRI portfolios is irrelevant.

The potential practical usefulness of this study is also significant. If different optimization techniques lead to different SRI portfolio performance, this would indicate that, apart from the social and environmental screening criteria, investors and fund managers also need to carefully consider the choice of asset allocation method. Financially savvy investment techniques and moral objectives need not be mutually exclusive. In fact, recognition of which optimization methods yield better results within SRI may enhance the growth of the SRI sector, leading to a larger share within the financial markets, and a lower cost of capital for the CSP champions. This, in turn, will strengthen the pressure from the financial markets for the adoption of sustainable practices by companies. Hence, our study can have profound consequences for professional fund managers, institutional and individual investors, corporations (particularly sizable and highly visible multinational enterprises - MNEs), pressure groups and NGOs.

The remainder of the paper is structured as follows: Section 2 reviews previous studies of the application of optimization techniques ${ }^{6}$ to forming SRI portfolios, and discusses the alternative portfolio construction methods which we compare and contrast. Section 3 contains details of the CSP database we use and the portfolio evaluation methods we employ. Section 4 presents our empirical results. Section 5 discusses the implications of our findings for the finance industry and the business world more broadly, and Section 6 concludes.

\footnotetext{
${ }^{6}$ We make use of the terms "technique", "approach", "model", "process" and "method" interchangeably in this regard.
} 


\section{Related literature, motivation of the study and development of hypotheses}

\subsection{Literature review and motivation of the study}

The vast majority of scholarly research dedicated to SRI portfolios focuses on identifying the ways in which they are different from (or similar to) conventional investments in terms of their constituents, the performance they achieve and the risks they bear. A surprisingly small number of academic papers have investigated ways in which the portfolio construction process, be it through the use of alternative security selection criteria or different optimization techniques, can lead to the generation of better performing, more efficient and stable SRI portfolios.

Barnett and Salomon (2006) shed some light on the optimal number and type of screening criteria used by SRI funds. Their findings depict a non-linear link between screening intensity and fund/portfolio performance. SRI portfolios, where just a few or many social screens are employed, outperform portfolios with an intermediate number of such screens. On the other hand, CapelleBlancard and Monjon (2014) investigate French SRI funds and find that "sin-stock" screens decrease financial performance, while other types of CSP screen do not have a noticeable financial impact on fund performance. In an effort to investigate the common claim that SRI funds are in reality nothing more than conventional funds in disguise, Kempf and Osthoff (2008) compare the sustainability characteristics of the portfolio holdings of SRI funds with those of conventional funds. Their analysis demonstrates that the social and environmental ratings of their constituent stocks are indeed higher than those of otherwise similar conventional funds.

Complimentary to this line of academic research is the small, and fairly new, literature dedicated to the use of alternative optimization approaches to construct well-diversified and efficient SRI portfolios. Hallerbach et al. (2004) were the first to present an interactive multiple goal programming approach for managing an investment portfolio where the decision criteria include social effects. An alternative approach was suggested by Drut (2012), who investigated whether adding restrictions regarding CSP when deriving optimal investment strategies leads to portfolios that underperform otherwise similar conventional investments. Drut concludes that the effects of adding a CSP constraint depend "on the link between the returns and the responsible ratings and on the strength of the constraint" (p. 28).

Ballestero et al. (2012) used goal programming within the framework of classical Markowitz meanvariance optimization to allow investors to take account of ethical issues, in addition to the 
standard financial information. Their analysis revealed that substantial green investment is generally outperformed by modest green investment - a rare result within the core empirical literature. The most recent relevant work in the area comes from Utz et al. (2014) who extended the Markowitz model by adding a social responsibility objective, in addition to the portfolio return and variance. They did not find any evidence that social responsibility, used as a third criterion, plays an important role in the financial outcome of asset allocation.

In short, the studies of the optimization techniques for SRI portfolios tend to focus, not on the effectiveness of the techniques themselves in creating well-performing portfolios, but rather on providing generic frameworks that integrate financial with social and environmental considerations. They investigate whether there is a financial cost to including these additional CSP considerations, and whether SRI portfolios tend to outperform or underperform otherwise similar conventional portfolios.

Contrary to the above, our study explores whether different methodologies which are applied in the generic professional investing arena lead to the construction of SRI portfolios with superior characteristics. We attempt to answer questions of the following type: Which asset allocation approaches lead to SRI portfolios which remain reasonably stable in terms of their constituent assets, thereby minimizing transaction costs? Does optimizing a different measure of risk and returns change the results? Or is performance of the various optimization methods broadly similar when forming SRI portfolios?

A common denominator of previous studies is the use of the Markowitz framework (or extensions of it) in the formation of SRI portfolios, and this has several important drawbacks. The application of Markowitz mean-variance optimization requires the estimation of the means, variances and covariances of the asset returns for the investment universe under consideration. In practice this means that, if the sample means and covariances are subject to estimation error, optimal portfolios constructed via Markowitz optimization can be unstable, and characterised by poor diversification and out-of-sample performance. This phenomenon has been well-substantiated in the portfolio selection literature (Broadie, 1993; Becker et al., 2015; Michaud, 1999; Ziemba and Mulvey, 1998). This is why it is important to study portfolios constructed using approaches that allow for estimation risk, and to compare their characteristics and performance.

The above argument applies to both conventional and socially responsible investing, but a strong case can be made that estimation errors in the input parameters are a more important issue when constructing SRI portfolios. There is a plethora of studies showing that CSP influences both asset 
returns (Brammer et al, 2006; Galema et al., 2008; Edmans, 2011; Hillman and Keim, 2001; Von Arx and Ziegler, 2014), and financial risk (Bouslah et al., 2013; Lee and Faff, 2009; Oikonomou et al., 2012). Both qualitative literature reviews (Margolis and Walsh 2003) and statistical metaanalyses (Margolis et al., 2009; Orlitzky et al., 2003) broadly substantiate this conclusion. Hence, CSP contributes to the estimation risk of the input parameters used in constructing portfolios. However CSP scores are subject to considerable estimation error, and this is for four reasons.

First, CSP is a concept which has proved very hard to define. Many definitions have been vague or too inclusive. In the words of Votaw (1973) 'the term is a brilliant one; it means something, but not always the same thing, to everybody'. The work of Carroll (1991) has been influential in defining CSP, and makes reference to a variety of tiers or levels of firm responsibilities that taken together constitute CSP. The European Commission on the other hand simply refers to CSP as a concept whereby "companies are taking responsibility for their impact on society"

Second, CSP is characterised by a large amount of variability and heterogeneity in its various dimensions making its accurate measurement a problematic task (Abbott and Monsen, 1979; Griffin and Mahon, 1997). CSP may be related to, inter alia, issues involving a firm's treatment of the natural environment, employee welfare, philanthropic activity, engagement with local societies and interaction with controversial industries.

Third, subjective judgements are involved, not only in assessing a company's performance in all of the above, but in measuring the relative importance of each CSP dimension for a firm belonging to a particular industry and operating within a specific socio-cultural environment. Hence, the quantification of CSP is a complex task which requires the collection and assessment of information both internal and external to the firm by sophisticated, independent assessors such as MSCI, Sustainalytics, Oekom and other agencies producing social ratings for companies.

Finally, CSP disclosures remain a discretionary part of corporate reporting in most countries $\left(\right.$ Orlitzky, 2013) ${ }^{8}$. Due to this, voluntary CSP reports are not subject to the same government oversight and regulatory scrutiny which applies to compulsory company reporting. Hence, erroneous or misleading CSP reporting may not lead to legal and financial sanctions, making such

\footnotetext{
${ }^{7}$ http://europa.eu/rapid/press-release_MEMO-11-730_en.htm
}

8 It should, however, be noted, that although CSP disclosures used to be very scarce (Lynn, 1992) they have become a lot more common. 
disclosures more susceptible to unintentional errors and deliberate manipulation by opportunistic firm managers (Edwards, 2008). This further complicates the issue of the accurate measurement of CSP.

Overall, whether it is due to the inherent definitional complexity and heterogeneity of CSP, or the subjectivity and misinformation surrounding CSP issues and a lack of regulatory scrutiny, there is an additional degree of ambiguity when considering CSP as criterion in portfolio creation. High (or low) reported CSP scores are likely to be subject to greater estimation error than more average scores. Since CSP scores are priced positively by financial markets, such over (under) estimation of the CSP scores biases the company's expected returns upwards (downwards), and may also bias its estimated variance downwards (upwards). Therefore companies with high (or low) CSP scores have higher estimation risk in their returns and risk. Because SRI portfolios are characterised by a greater degree of estimation errors in the input parameters, i.e. return and risk, an optimization method which is less sensitive to these values should be employed. However, the SRI literature is lacking in providing meaningful suggestions, and this is the gap our study attempts to fill.

\subsection{Optimization methods and research hypotheses}

There are various alternative portfolio optimization frameworks which could be used for the construction of SRI portfolios with desirable properties. We apply six of these frameworks, all of which are widely known and commonly considered by the professional portfolio management community. Each framework has a different underlying rationale, and may lead to the construction of portfolios with different characteristics. Though dozens of different optimization techniques are available, we believe the six we use are an appropriate representation of the broad alternative rationales behind asset allocation mechanisms. The first three of the approaches below (Markowitz, robust estimation, and Black-Litterman) are "classical", quantitatively sophisticated models, whereas the other three (naïve diversification, risk parity, and reward-to-risk) are more recent approaches with a less solid mathematical basis, and draw largely on basic investing intuition. Below, we provide an explanation of the rationale behind these approaches and a broad outline of their implementation. The technical details of each framework are in Appendix A.

\section{i) Markowitz portfolio optimization}

In spite of the various problems we have outlined, the Markowitz (1952) portfolio optimization technique is the forefather of the vast majority of modern portfolio construction methods 
(Alexander, 2009), and usually serves as the basis for the comparison of the performance of different models. Markowitz was the first to formally recognise the importance of diversification, and to create a method whose principal premise is that only the first two moments (mean and variance) of the return distribution are important to investors. There have recently been calls for a return to Markowitz's model of portfolio construction (Kaplan, 2014), with explicit risk and expected return assumptions, instead of the implicit assumptions made by many of the alternative methods.

\section{ii) Robust estimation}

A sophisticated set of portfolio construction practices, which has been used when considering "conventional" (i.e. non-SRI) assets, involves imposing norm constraints on the portfolio weights to obtain the desired characteristics (see, for instance, Ledoit and Wolf, 2003 and 2004; Fan et al., 2008). We elect to use a technique that falls within this category, and adopt a robust portfolio technique, inspired by Xing et al. (2014) among others, to construct superior portfolios in the presence of estimation risk which, as we noted above, is higher when creating SRI portfolios. This approach encourages the creation of sparse portfolios with relatively few active positions and significantly reduced associated transaction costs.

\section{iii) Black-Litterman}

The Black-Litterman (1992) asset allocation model is another approach commonly employed by a variety of financial institutions. It is particularly popular among active money managers "who believe they hold information superior to that of other market participants, but wish to update their beliefs using market prices" (Gofman and Manela, 2012). The main advantage of this model is that it allows the investor to combine the market equilibrium with the views of the investor. In the words of He and Litterman (1999), the intuition underlying this approach can be summed up as: "the user inputs any number of views, which are statements about the expected returns of arbitrary portfolios, and the model combines the views with equilibrium, producing both the set of expected returns of assets as well as the optimal portfolio weights".

\section{iv) Naive diversification $(1 / \mathrm{N})$}

The naive diversification approach is based on the very simple rule whereby $1 / N$ of the investor's wealth is allocated equally to each of the $N$ assets available in the investment universe being considered. This method does not attempt to assign asset weights to optimize the risk-return tradeoff. Instead, the most appealing feature of the naive approach lies in its simplicity, as it does not require the estimation of expected returns, covariances, or higher moments of asset returns. In 
addition, the previous literature provides evidence that the naive diversification $(1 / N)$ approach is not inferior to sample-based mean-variance models (Bloomfield, Leftwich, and Long, 1977), or even to most of the extensions of the Markowitz optimization framework (DeMiguel et al., 2009b).

\section{v) Risk-parity portfolios}

In recent years the risk-parity portfolio approach has attracted significant interest from academics and practitioners, and is widely applied by long term institutional investors such as pension funds, and insurance companies, as well as mutual funds (Anderson, Bianchi and Goldberg, 2012). In its simplest form, it leads to a portfolio of risky assets where the weights are anti-proportional to each asset's variance of returns (i.e. total risk). The risk-parity approach benefits from the fact that assets with high volatility usually earn a lower premium per volatility unit that those with lower volatility (Baker et al., 2011; and Frazzini and Pederson, 2014).

\section{vi) Reward-to-risk timing portfolios}

The reward-to-risk timing portfolio strategy has been proposed by Kirby and Ostdiek (2012). Its development was motivated by the finding that naive diversification portfolios tend to outperform mean-variance optimization approaches, which may be due to the instability of the portfolios created by Markowitz-style methods. Hence, Kirby and Ostdiek (2012) created an alternative method which leads to more stable portfolios with lower transaction costs. The reward-to-risk timing strategy allocates asset weights in proportion to the contribution of each asset's meanvariance ratio to the mean-variance ratio of the entire universe of assets.

Further techniques for deriving optimal portfolio strategies which might have been considered include: stochastic programming, e.g. Geyer and Ziemba (2008); dynamic programming, e.g. Rudolf and Ziemba (2004); and stochastic simulation, e.g. Boender (1997). However, they are computationally challenging, making them inappropriate for use in practice for the sizeable portfolios we consider. For instance, Platanakis and Sutcliffe (2017) mention that the number of scenarios required by stochastic programming exceeds 24 billion for a portfolio with just 14 assets, four non-overlapping investment periods and five independent outcomes for each uncertain parameter per estimation period. With 100 assets (firms) this figure rises to $3.1554 \times 10^{70}$. As a result these techniques are not used in our study due to the computational load they would entail.

In the field of SRI, it could be argued that the nature of the non-financial (i.e. CSP related) screening criteria used is of the utmost importance; and the significance of the CSP scores far outweighs the importance of which optimization method is selected. This assertion explains why 
the SRI field is thought of as being "too qualitative", and involving "too much subjective judgement" (Grene, 2016). No empirical testing of this contention has been conducted so far. A necessary condition for this assertion to be true it that the choice of optimization technique has a substantial effect on the performance of SRI portfolios.

Hypothesis 1: In an SRI screened investment universe, different types of optimization methods create portfolios with substantially different performance.

A more interesting and important question is which optimization approaches are likely to perform best within the SRI universe. In order to formulate a relevant hypothesis, we first need to take a look at the conclusions reached by the conventional asset literature. In brief, while contradictory results exist regarding the relative effectiveness of different optimization techniques, there is considerable evidence which supports naive portfolio selection methods such as $1 / N$. When comparing the performance of a range of different methods, including $1 / N$, Markowitz, risk parity and minimum variance; Board and Sutcliffe (1995), Zhu (2015) and Jacobs et. al. (2014) found mixed results with no clear winner.

However, there is more positive evidence. Bloomfield et al (1977) found that naive portfolio allocation methods are superior to more sophisticated methods, and that $1 / N$ performs well; while Jorion (1991) demonstrated that $1 / N$ is superior to the sophisticated techniques of Markowitz, Bayes-Stein and minimum variance. More recently, Barroso (2015), Duchin and Levy (2009), Jagannathan and Ma (2003), Kan et al (2016) and Pflug et al (2012) show that $1 / N$ is superior to Markowitz; Windcliff and Boyle (2004) find that $1 / N$ is preferable to both Markowitz and BayesStein, and Fischer and Gallmeyer (forthcoming) demonstrate the superiority of $1 / N$ to minimum variance. Kirby and Ostdiek (2012) point out that the stability of naive diversification is one of the main causes behind its strong performance, and that the reward-to-risk approach can yield stronger results, even in the presence of high transaction costs. Finally, Ang (2014) and Chaves et. al. (2011) find that the naive methods of $1 / N$ and risk parity are superior to both Markowitz and minimum variance. Therefore, the literature for general portfolios tends to support the use of naive rather than sophisticated portfolio selection techniques. Given the increased importance of estimation risk for CSP information (see section 2.1), we hypothesise that the situation may be very different for SRI portfolios. The more simplistic optimization methods make no effort to combat the problems caused by estimation risk, whereas the more formal approaches - in spite of their relevant shortcomings - do better in this regard. Hence we posit: 
Hypothesis 2: In an SRI universe, quantitatively sophisticated optimization methods lead to better performing porffolios than do naïve approaches.

To summarise, we consider a variety of widely applied modern portfolio construction approaches with different points of emphases and supporting rationales, and conduct a horse race between them using a socially responsibly screened universe of stocks. The next section discusses the portfolio evaluation measures we use, and then describes the CSP data which allows us to identify sustainable/responsible equity investments.

\section{Performance measures and dataset}

\subsection{Portfolio evaluation metrics}

We compare the impact of the different portfolio construction techniques on socially responsible investments along the following dimensions: risk, risk-adjusted returns, level of diversification and stability of asset weights. We use different metrics to capture alternative aspects of the first two of these dimensions and to ensure the convergent validity of these comparisons. The performance evaluation metrics we use will now be explained.

\section{i) Risk}

We use the annualized mean standard deviation of portfolio returns as it is the most common measure of total risk. However, although the standard deviation is an appropriate measure of risk for normal (or at least symmetric around the mean) distributions of returns, it may lead to erroneous conclusions in skewed distributions. This is because it treats deviations above and below the mean in the same way, although only the latter should be a source of concern for investors. Hence, we use the annualised mean standard deviation only for negative returns, which is the semistandard deviation that Markowitz (1991) identified as a "more plausible measure of risk".

We also use the Value at Risk (VaR) measure which is commonly used for financial risk management purposes. VaR captures the maximum monetary (or percentage) loss for a given investment horizon and a specified probability level, indicting the loss for outcomes in the extreme left tail of the distribution, i.e. the worst outcomes. We use a $99 \%$ probability level (i.e. focusing on the worst 1\% scenarios) and an investment horizon equal to our out-of-sample period (2001 until 2011). Along similar lines we use the $99^{\text {th }}$ percentile conditional value-at-risk, which is defined as the expected value of the portfolio's returns that do not exceed the possible losses, as indicated by the standard VaR. 
Finally, drawdown measures are popular in the asset management industry, and are often used by commodity and hedge fund traders (Eling and Schuhmacher, 2007), as well as by institutional investors such as pension funds (Berkelaar and Kouwenberg, 2010) to assess the magnitude of large potential drops in portfolio returns. The maximum drawdown rate measures the drop from the highest point in cumulative portfolio returns over a certain time horizon (we use the entire out-of-sample period of twelve years), and is a measure that does not depend on distributional assumptions.

\section{ii) Risk-adjusted performance}

Optimization methods maximise the portfolio's risk-adjusted performance. However, since there is no consensus on the most appropriate way to measure returns or risk, or how to combine the two in order to measure their trade-off, many different metrics have been proposed and used. The simplest ratio to calculate is the ratio of mean portfolio returns divided by their standard deviation - effectively a Sharpe ratio with a zero risk-free rate (Sharpe, 1994). A more advanced metric, which is an extension of the Sharpe ratio, has been proposed by Dowd (2000). This measure is calculated by dividing the mean return by the VaR of the portfolio, and Dowd (2000) provides several numeric examples which demonstrate its superiority over the Sharpe ratio. Another version of the Sharpe ratio is the Sortino ratio which uses only downside risk (as captured by the semi-standard deviation) instead of total risk (Rollinger and Hoffman, 2014). This modification avoids the paradoxical investment choices brought about by non-normality of the distribution of asset returns. We also calculate the Omega ratio (Shadwick and Keating (2002) which is defined as the probability weighted ratio of gains versus losses for some threshold return target (we use zero, as is common practice). One of the main benefits of this metric over the alternatives is that, by construction, it considers all the moments of the empirical distribution of returns.

In a final set of portfolio performance metrics we divide portfolio returns by the average drawdown to capture significant price falls from previous peaks. A few similar, but distinct, measures have been used for this purpose. The standard metric is the Sterling ratio, which measures the average return divided by the average drawdown for an investment period, Bacon (2008). We also make use of the Calmar ratio, which is the average annual return divided by the maximum drawdown for the entire out of sample period. Young (1991) concludes that the Calmar ratio is superior because it changes gradually, leading to a smoothing of the portfolio's risk-adjusted performance, especially when compared to the Sterling and Sharpe ratios. As a final variation, we use the Burke ratio by taking the difference between the portfolio return and the risk free rate, and 
dividing it by the square root of the sum of the square of the drawdowns (Burke, 1994). Although these three measures are positively correlated, they are distinct, and can lead to moderately different empirical evaluations of portfolios produced via different approaches.

\section{iii) Diversification and stability}

SRI requires additional screening of the universe of investable assets using non-financial criteria (positive, negative, and best-in-class screening are indicative approaches), and the ambiguity in companies' CSP scores makes it more likely that this process will lead to greater estimation risk in their inputs to portfolio models. Therefore it may be harder to create SRI portfolios which effectively reduce idiosyncratic risks through diversification than it is for non-SRI portfolios. So examining the way in which the portfolio optimization process influences this characteristic is important for our analysis. We measure the diversification of the portfolios by summing up the squared portfolio weights for each constituent and each estimation period, following Blume and Friend (1975).

In addition, a portfolio construction approach which results in substantial rebalancing each period leads to significant transaction costs that reduce returns. So the stability of the resulting portfolio also needs to be examined. Following Goldfarb and Iyengar (2003), the portfolio stability between two successive investment periods is measured by summing the squares of the differences between each asset's portfolio weights in adjacent investment periods.

\subsection{Dataset}

To create SRI portfolios we use CSP metrics constructed using the MSCI ESG STATS database? In the relevant research this dataset is the most frequently used, and has been characterised as "the best-researched and most comprehensive" (Wood and Jones, 1995) in this field, as well as "the de facto research standard at the moment" for measuring CSP (Waddock, 2003, p. 369). It is a multi-dimensional CSP database rich in both the cross section of firms analysed (currently about 3,000 US firms) and the timespan covered (23 years), and has been shown to be characterised by reliability, consistency and construct validity (Sharfman, 1996).

\footnotetext{
${ }^{9}$ Known as KLD STATS before the acquisition of KLD (as part of RiskMetrics) by MSCI in 2010.
} 
As with any effort to quantify something as elusive and multifaceted as CSP, MSCI ESG STATS is not without limitations. The reliability of the process of collecting data related to CSP and using the respective information to produce the CSP scores has been scrutinised by critiques of social responsibility; both in general and the MSCI ESG STATS specifically (Entine, 2003). An additional concern arises when considering the best way that the various dimensions of CSP captured by MSCI ESG STATS (for example environmental issues and firm relations with local communities) can be aggregated into a single metric, irrespective of the industry in which a firm operates (Entine, 2003). Mattingly and Berman (2006) have also pointed out various taxonomies and correlations which emerge within the different aspects of this database which need to be treated carefully in empirical research. Despite all the above, the MSCI ESG STATS database remains one of the most frequently used CSP databases in the field of financial economics (Krüger, 2015). Notable examples of its usage in seminal papers in the past few years include Krüger (2015) who studies the short-term market reaction to CSP information; Harjoto, Jo, and Kim (2015) who investigate the links between CSP, institutional ownership and volatility; Di Giuli and Kostovetsky (2014) who show that the political views of CEOs play a role in the CSP achieved by the firms they are managing; and Deng, Kang, and Low (2013) who provide evidence of the value relevance of CSP for acquirers in M\&A deals. Given the long history of the use of MSCI ESG STATS in this field, its very extensive coverage of US firms and, especially, the long time-series of data it provides (which is a necessity for our work), we elect to use it in our study.

The MSCI ESG STATS data contains annual assessments of the societal and environmental policies and practices of US corporations since 1991. Firms from every sector and industry are assessed on a plethora of indicators relevant to distinct aspects of CSP, which are referred to as "qualitative issue areas". These are: community relations, diversity in the workplace, treatment of employees, environmental issues, product (or services) level of safety and quality, corporate governance framework, and respect for human rights. The relevant assessment is done separately on positive aspects ("strengths") and controversial aspects ("concerns") for each qualitative issue area. Sources both internal to the companies (e.g. proxy statements, quarterly reports and other firm documentation) and external to them (e.g. articles in the business and financial press, periodicals, and general media) are used to conduct the assessments of their social performance. In 1991 the dataset covered 650 firms, including all the firms listed in the S\&P 500 Composite Index and the Domini 400 Social Index (now the MSCI KLD 400 Social Index). In 2001 this number grew as the relevant universe incorporated the largest 1,000 US companies in terms of market value. Expansion continued in 2003 with the inclusion of the 3,000 largest US firms. Since 
2003 the number of firms in the dataset has remained stable at approximately 3,000, and this dataset is available to us until 2011.

We follow the relevant empirical work which uses the MSCI ESG STATS database (Hillman and Keim 2001; Oikonomou et al., 2012; 2014) and focus solely on those qualitative business issues that can be directly connected with primary stakeholder groups. This is based on the stakeholder theory framework developed by Clarkson (1995) which broadly posits that strong collaborative links with those stakeholder groups that are essential to the firm's viability and operational wellbeing (i.e. the primary stakeholders) are the only ones that will produce tangible financial benefits to the firm. Hence, the CSP measures used to create SRI portfolios are based on those qualitative issue areas considered important for effective stakeholder management with local communities, employees (including diversity issues), customers and environmental groups/activists (Hillman and Keim, 2001). An outline of the five indicators used in the assessment of each CSP issue area we are interested in can be found in Appendix B.

For the core part of our analysis we construct aggregate measures of CSP for each firm-year observation in the MSCI ESG STATS universe between 1991 and 2011. For each of the five issue areas of interest we sum all the indications for social strengths and deduct the sum of the respective indications for social concerns for a given firm in a given year. Then we calculate the arithmetic average of all five of these scores in order to create a single, multidimensional CSP rating indicative of the firm's overall social and environmental profile. Creating such a multidimensional CSP measure raises questions about the appropriate way to weight each dimension (i.e. the relative importance of each dimension). The common practice in the literature is to use equal weighting (Deng et al., 2013; Oikonomou et al, 2012) which is what we do. In addition, as a robustness check in subsection 4.3 we look at robust SRI portfolios based on individual CSP dimensions to investigate whether our results can be replicated using each of the five individual CSP measures. Our approach follows previous scholarly work in the area of CSP and finance (Jo and Harjoto, 2012 and Deng, Kang and Low, 2013 being two notable examples). Finally, based on these aggregated CSP scores, we estimate the ranking of each firm across the entire universe covered by MSCI (formerly, KLD) in a given year, and average this relative ranking across the years when the firm is included in the database. We exclude firms for which we cannot construct aggregate scores for at least 10 years out of the 22 in our sample, which helps to ensure the robustness and consistency of the CSP standing of each company. This process results in the estimation of average, aggregate, CSP rankings for 1,362 US firms. We identified the 100 firms with the highest 
CSP scores as the sub-set of CSP screened firms ${ }^{10}$. This ensures that we have a large enough number of stocks to benefit from the risk reducing effects of diversification when we form portfolios which consist entirely of the top CSP performers. We match this dataset with total returns (i.e. returns that include dividends) for these firms from Thomson Reuters DataStream.

\section{Results}

\subsection{Main results}

Due to the smaller coverage of firms by KLD during its earlier stages, as well as missing observations for quite a few firms over that period, it is not feasible to include years prior to 1993 in the data. Furthermore, KLD data is available to us up to 2011 (inclusive). Tables 1 and 2 depict the details of the estimation and investment periods (in months) we use to evaluate the SRI portfolios. Each three year out-of-sample period is preceded by its six year estimation period.

\begin{tabular}{c|ccc}
\hline Periods(t) & Start & End & Length \\
\cline { 1 - 1 } Estimation Period 1 & 1994M1 & 1999M12 & 72 \\
\cline { 1 - 1 } Estimation Period 2 & 1997M1 & 2002M12 & 72 \\
\cline { 1 - 1 } Estimation Period 3 & 2000M1 & 2005M12 & 72 \\
\cline { 1 - 1 } Estimation Period 4 & 2003M1 & 2008M12 & 72 \\
\hline
\end{tabular}

Table 1: Six-Year Estimation Periods

\begin{tabular}{c|ccc}
\hline Periods(t) & Start & End & Length \\
\cline { 1 - 1 } Investment Period 1 & 2000M1 & 2002M12 & 36 \\
\cline { 1 - 1 } Investment Period 2 & $2003 \mathrm{M} 1$ & $2005 \mathrm{M} 12$ & 36 \\
\cline { 1 - 1 } Investment Period 3 & 2006M1 & $2008 \mathrm{M} 12$ & 36 \\
\cline { 1 - 1 } Investment Period 4 & 2009M1 & $2011 \mathrm{M} 12$ & 36 \\
\hline
\end{tabular}

10 Our choice to retain the same list of firms for all four of the estimation periods is based on both conceptual and empirical/practical issues. First, there is a general consensus in the strategic management literature studying CSP that its economic/financial benefits accrue in the long-run and require consistency on the part of the firm (Barney and Hansen, 1994; Waddock and Graves, 1997; Hillman and Keim, 2001). The strategic benefits of CSP are built via consistently good social and environmental performance over an extended period of time which leads to better relations with stakeholders. Therefore we used the firms with the highest average CSP ranking across the period of interest instead of one year of data. Second, it has been well-documented that CSP in general, and CSP as captured in the MSCI ESG STATS (KLD) database in particular, tends to be reasonably stable for a given firm over time, with most of the variation arising in the cross-section, not the time-series. This relative stability in CSP leads to a reasonably stable ranking order that is even more pronounced at the top of the list - meaning that CSP champions tend to remain the same across years. These are exactly the firms we are investigating. 
Table 2: Non-Overlapping Three-Year Investment Periods

In the literature, the length of the estimation period varies, but five to ten years is generally considered to be appropriate. For instance, Xing et al. (2014) use rolling windows of five years (60 months), ten years (120 months) and 15 years (180 months) to evaluate out-of-sample performance; DeMiguel et al. (2009a) use ten years (120 months); DeMiguel et al. (2009b) use ten years (120 months), 30 years (360 months) and 500 years (6,000 months) to evaluate the out-ofsample performance of simulated data, while Platanakis and Sutcliffe (2017) use a six year (72 months) rolling window. The choice of a six year estimation window which starts in 1994M1 and ends in 1999M12 for the first estimation period lies within the range used by previous studies.

We use out-of-sample investment periods of three years. We believe this to be a reasonable investment span within the area of SRI for two reasons. First, we know that a significant part of the demand for SRI comes from long term institutional investors (pension funds and insurance funds, as noted by Cox et al., 2004). These investors have long investment horizons, and generally apply buy-and-hold strategies for long periods (Ryan and Schneider, 2002). Second, the extant literature argues that CSP leads to the creation of comparative advantages that become economically valuable in the long run (Cox et al, 2004; Hillman and Keim, 2001; Waddock and Graves, 1997); while in the short run it may not yield any tangible financial benefits to the firm and investor. While there is no consensus in the SRI literature on when the financial effects of CSP start materializing, there is evidence that this takes longer than a year, and possibly longer than five years (see Oikonomou et al, 2014 where they investigate the sensitivity of the impact CSP to the investment horizon of bond holders). In view of this evidence that the effects of CSP take between one and five years to materialise, and in order to have multiple investment periods in our out-of-sample analysis, we use a three year period in our analysis. As a robustness check we repeat the analysis using a one year investment period.

We use data for the first estimation period to compute the optimal portfolio for each method for the following three years (first investment period). Then we roll the data forward by 36 months, so that the second estimation period is now used to compute the optimal portfolio for the second investment period, and so on; providing a total of four out-of-sample test periods of three years each, or 144 out-of-sample months (12 years) in total ${ }^{11}$. Notice we have ruled out negative asset

\footnotetext{
11 When the number of assets exceeds the number of observations in an estimation period, the inverse covariance matrix, which is required only for the estimation of the Black-Litterman model, is approximated using appropriate algorithms within MATLAB (e.g. the LU decomposition).
} 
weights (or short sales), as institutional investors (who are responsible for the majority of demand for SRI) do not in principle engage in short selling.

\begin{tabular}{|l|c|c|c|c|c|c|}
\hline Performance Measures & Markowitz & Robust & $\begin{array}{c}\text { Black- } \\
\text { Litterman }\end{array}$ & 1/N & $\begin{array}{c}\text { Risk } \\
\text { Parity }\end{array}$ & $\begin{array}{c}\text { Reward- } \\
\text { to-Risk }\end{array}$ \\
\hline Risk Measures & & & & & & \\
\hline Mean standard deviation & 0.1352 & 0.1317 & 0.1748 & 0.2119 & 0.1657 & 0.1547 \\
\hline Mean downside standard deviation & 0.0910 & 0.0894 & 0.1016 & 0.1483 & 0.1193 & 0.1159 \\
\hline VaR(99\%) & 0.1216 & 0.1216 & 0.1323 & 0.2305 & 0.1844 & 0.1800 \\
\hline Conditional VaR(99\%) & 0.1434 & 0.1420 & 0.1341 & 0.2432 & 0.2071 & 0.2107 \\
\hline Maximum Drawdown Rate & 0.3078 & 0.3056 & 0.2112 & 0.6382 & 0.5237 & 0.5439 \\
\hline Risk-Return Trade-Off & & & & & & \\
\hline Mean Risk-Adjusted Returns & 0.4002 & 0.4183 & 0.5009 & 0.0667 & 0.1438 & 0.0736 \\
\hline Dowd Ratio & 0.0371 & 0.0378 & 0.0551 & 0.0051 & 0.0108 & 0.0053 \\
\hline Sortino Ratio & 0.5943 & 0.6162 & 0.8614 & 0.0953 & 0.1998 & 0.0983 \\
\hline Omega Ratio & 1.3717 & 1.3926 & 1.5144 & 1.0557 & 1.1253 & 1.0614 \\
\hline Sterling Ratio & 0.0937 & 0.0974 & 0.2030 & 0.0102 & 0.0211 & 0.0083 \\
\hline Calmar Ratio & 0.0146 & 0.0150 & 0.0345 & 0.0018 & 0.0038 & 0.0017 \\
\hline Burke Ratio & 0.0017 & 0.0018 & 0.0032 & 0.0003 & 0.0005 & 0.0002 \\
\hline Diversification and Stability & & & & & & \\
\hline Mean Diversification & 0.0940 & 0.0813 & 0.1282 & 0.0100 & 0.0152 & 0.0248 \\
\hline Mean Stability & 0.0910 & 0.0690 & 0.2083 & 0.0000 & 0.0019 & 0.0155 \\
\hline
\end{tabular}

Table 3: Comparison of the performance of six different portfolio construction approaches across fourteen different metrics. Initial investment universe of 100 consistently high performing CSP firms. Estimation period of six years and out-of-sample period of twelve years. VaR stands for Value at Risk, and $1 / N$ is the naive diversification approach

Table 3 contains the core of our empirical results, and compares the performance of the six portfolio construction methods we employ (Markowitz, robust estimation, Black-Litterman, naïve diversification $(1 / N)$, risk parity, and reward-to-risk) on the universe of the best 100 CSP performers. We restrict the universe to 100 firms as a reasonable compromise between having firms which do not really constitute the "cream of the crop" in terms of CSP, and having insufficient firms to effectively study the difference in the impact of the optimization methods on the performance of the SRI portfolios. The performance of these portfolios, formed in six different ways, is compared using 14 criteria which examine risk (five measures), risk-adjusted returns (seven measures), diversification, and portfolio stability. The comparisons are made over the 144 out-of-sample months (12 years) which include four investment periods ( $4 \times 36$ months), with different optimal portfolios applying for each three year period (36 months). The results are 
adjusted to present annualized figures (where applicable), as is the norm in the asset management industry.

Focusing on risk, the robust estimation approach produces the least risky SRI portfolios in terms of total risk (mean standard deviation), total downside risk (mean downside standard deviation) and $\mathrm{VaR}$, while it comes second to the Black-Litterman approach in terms of conditional $\mathrm{VaR}$ and maximum drawdown. The Markowitz model also performs well, finishing second or third in almost all of the risk metrics, and ties first on $\mathrm{VaR}$. On the other hand, the naive diversification $(1 / N)$ approach consistently produces the riskiest portfolios across all the measures, with the risk parity and reward-to-risk approaches also producing high risk portfolios. The differences between the scores of the most and least risky portfolios are substantial. In terms of total risk, the robust estimation approach leads to an SRI portfolio with an average annualised standard deviation of returns of $13.17 \%$, whereas the equivalent number for the naive diversification approach is $21.19 \%$, i.e. over $60 \%$ higher; while the $\mathrm{VaR}$ score for the $1 / \mathrm{N}$ portfolios is $90 \%$ higher than for robust estimation. The maximum drawdown for the "risky" naive diversification SRI portfolio is over 100\% larger than for the "safe" Black-Litterman SRI portfolio. These observations are particularly important for the risk-averse, long-term institutional investors who form a significant portion of the demand for SRI.

Focusing on the risk-return trade-off, analysis of the extensive array of metrics we have used produces a very clear picture. It terms of portfolio risk-adjusted returns (Dowd ratio, Sortino ratio, Omega ratio, Sterling ratio, Calmar ratio and Burke ratio), the Black-Litterman model leads to the best out-of-sample performance, with robust estimation ranking second. At the other end of the spectrum, the naive diversification and reward-to-risk methods produce the worst risk-return ratios. Once more, the differences in the extremes are quantitatively large. For example, the value of the Dowd ratio for the portfolio produced using the Black-Litterman method is 0.0551 , while for the "naive" portfolio it is just 0.0051 (i.e. less than one tenth of the value of the former). Similarly, looking at the Sterling ratio, the Black-Litterman approach again produces the best result with a value of 0.2030 , which is more than 20 times larger than the corresponding result of 0.0083 for the reward-to-risk method. Comparisons across the other risk-return metrics corroborate this conclusion.

The picture changes when looking at the diversification and stability of portfolio constituents. By construction, the naive approach leads to an equal weighting of all the assets in the investment universe (a 1\% investment in all 100 firms in our case), and this remains stable in every period. Hence it leads to the optimal diversification and stability scores for the metrics we utilize. What is 
interesting is that the second best approach with regard to these aspects is risk parity, whereas Black-Litterman (which led all the other models in terms of riskiness and risk-return tradeoff) performs the worst, and the Markowitz model is the second worst. So, although the more quantitative portfolio optimization techniques (Black-Litterman, robust estimation and Markowitz) lead to less risky portfolios which provide higher returns per unit of risk taken, they are also associated with less diversification and require more significant rebalancing of their constituent assets. The exact opposite is true for the more simplistic portfolio construction techniques which are based on fundamental investment intuition (naive diversification, risk parity and reward-to-risk). It should be noted that we have four triennial investment periods, and the limited number of observations does not allow us to conduct reliable tests of statistical significance for the differences between the risk-adjusted returns. However, the economic significance of our results, especially those related to risk-adjusted performance, is of such a magnitude that it is hard to dismiss.

We now examine some key characteristics the 144 month time series of returns for the different approaches. We focus first on risk, and look at drawdown rates. As can be seen in Figure 1, for the majority of the 12 year evaluation period, all the approaches lead to portfolios with reasonably similar drawdown rates. However, from the start of the global financial crisis (late 2007), the drawdown rates of the different models diverge significantly. The Black-Litterman approach is consistently associated with the lowest drawdown, followed by the Markowitz and robust estimation approaches (with almost identical drawdown), whereas naive diversification, risk parity and reward-to-risk have much higher drawdown rates during this period. 


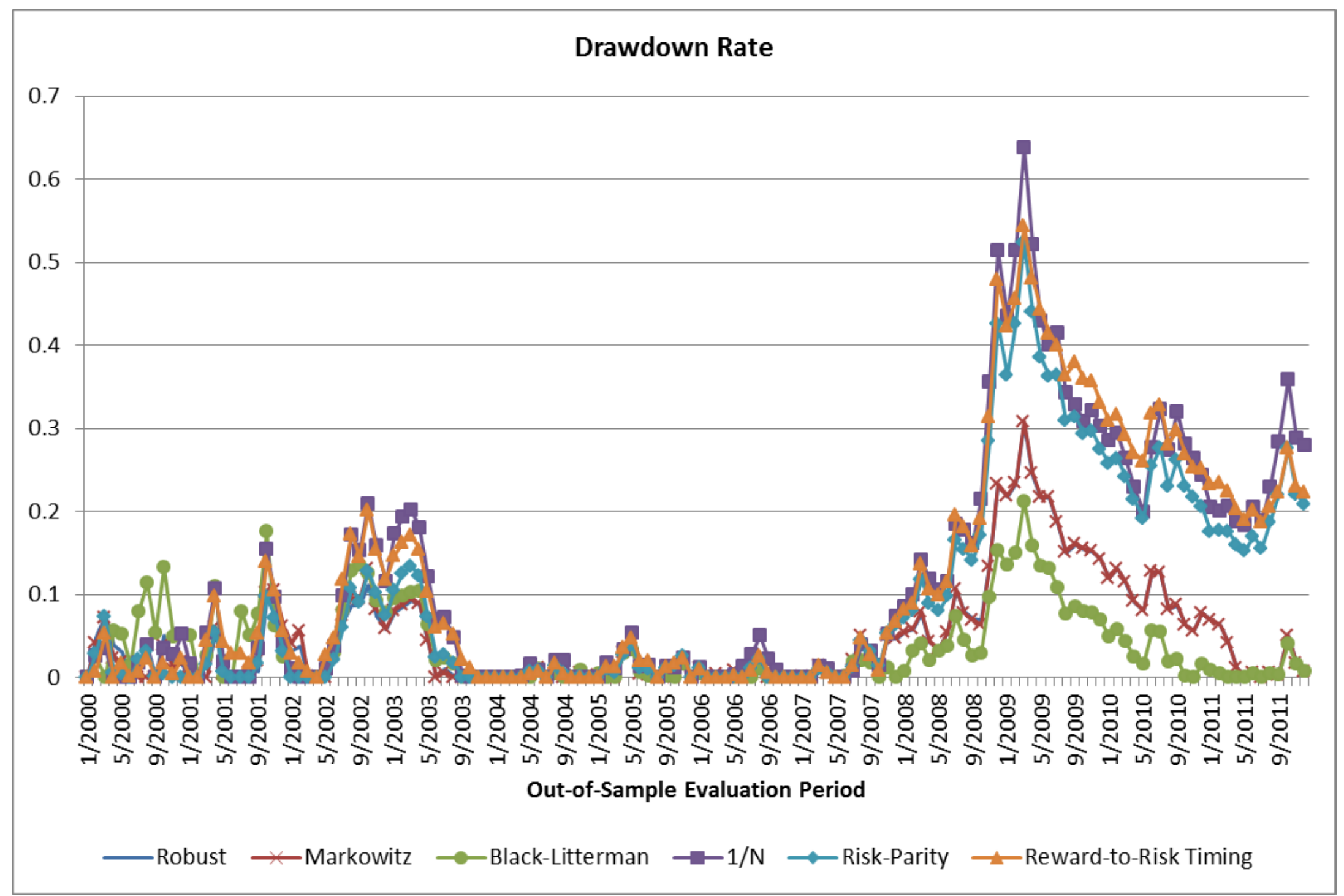

Figure 1: Comparison of the drawdown rate of SRI portfolios constructed using the six different portfolio construction approaches over the 12 years of the out-of-sample period. 
Figure 2 shows the cumulative wealth associated with the different strategies. The Black-Litterman approach dominates all the other strategies in terms of cumulative wealth throughout the entire 12 years (2000-2011). After the first two years the Black-Litterman portfolio clearly moves ahead of its rivals, and over time gains a significant advantage which it maintains irrespectively of the overall direction of the market. Once more, the naive diversification, risk parity and reward-to-risk approaches perform worst, while the robust estimation and Markowitz models are somewhere in between the best and worst performing strategies (and trend so closely together that are nearly indistinguishable as in Figure 1). Given that all these portfolios are "long only" (i.e. no short-selling of assets, or negative weights), it is to be expected that the cumulative wealth for all strategies falls in 2008 and 2009 when the financial markets were collapsing, before it starts climbing again. 


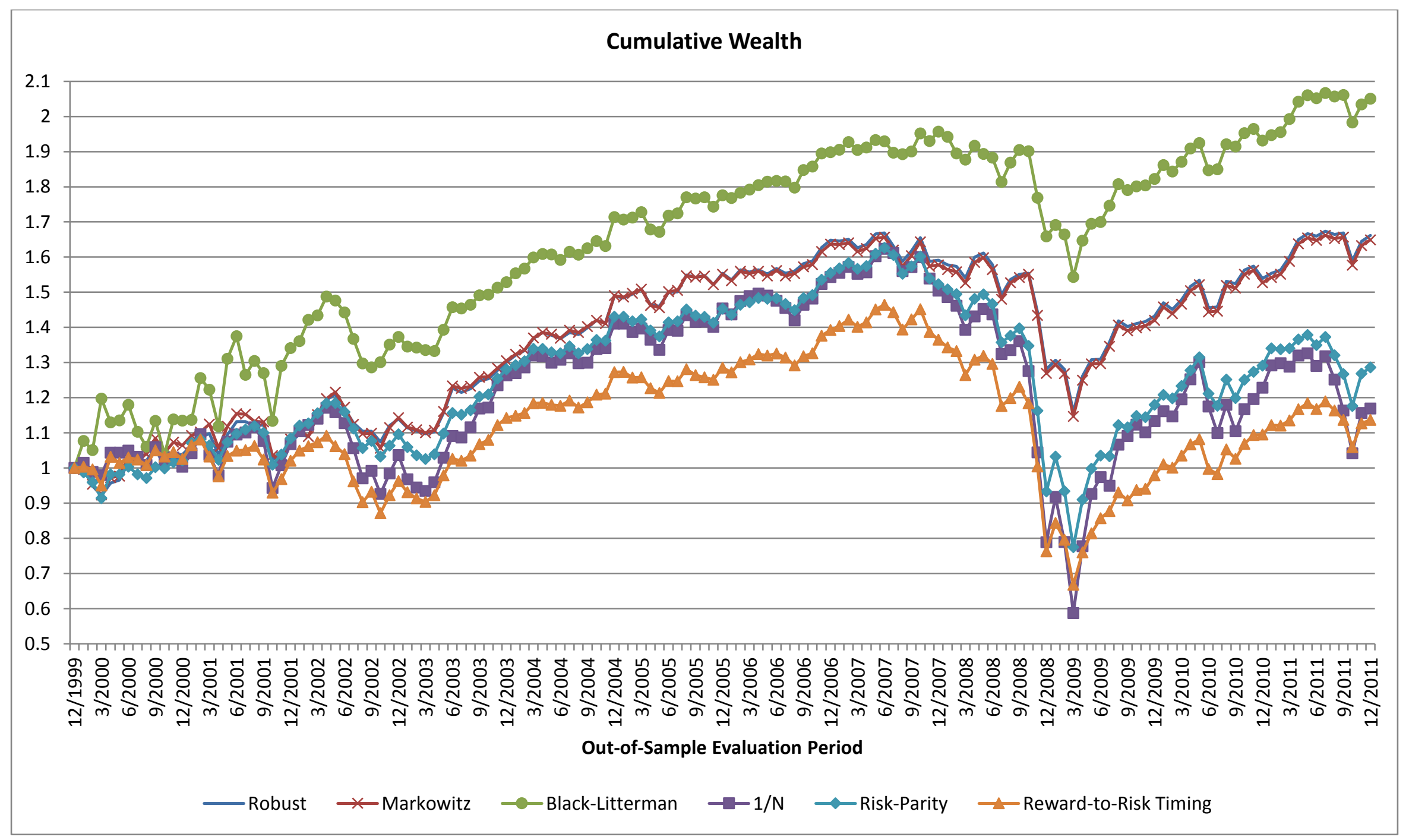

Figure 2: Comparison of the cumulative wealth of SRI portfolios constructed using the six different portfolio construction approaches over the 12 years of the out-of-sample period. 
Finally, in Figure 3 we provide a comparison of the distribution of asset weights for the SRI portfolios constructed using five different portfolio approaches (we do not include the assets of the $1 / \mathrm{N}$ approach as they are all assigned a $1 \%$ weight). This shows the size distribution of asset weights across the four investment periods. Only weights of $1 \%$ or more are presented in Figure 3 , as this is a rule-of-thumb cutoff point for professional asset managers. The weights are average values across the four investment periods. The Markowitz, robust estimation and Black-Litterman models all lead to portfolios with exactly 26 assets. However, the identity of these assets is not the same across these three approaches, and the size distribution of asset weights is also different. The distribution of asset weights is very similar for the Markowitz and robust estimation approaches, with comparable maxima (10.88\% and $11.13 \%$ respectively), and six assets with weights of $4 \%$ or more in each portfolio. On the other hand, the Black-Litterman portfolio has a lower maximum weight $(8.79 \%)$, and eight assets with weights of approximately $4 \%$ or more. The risk parity and reward-to-risk techniques lead to portfolios with more assets and lower average weights. The risk parity portfolio comprises 42 assets with a weight of $1 \%$ or more, and a maximum weight of just $3.56 \%$; while the reward-to-risk portfolio contains 39 assets with a maximum weight of $3.95 \%$. So, although the three less formal optimization models create portfolios which are more stable and require less rebalancing across investment periods, they also contain a greater number of assets compared to the more formal optimization methods. Hence, no clear conclusion can be drawn about the overall impact that transaction costs would have from this analysis.

To investigate this further, we computed the value of shares traded at the start of each of the four out-of-sample periods for each of the six methods. Assuming transactions costs to be $1 \%$ of the value of shares traded, we computed the total transactions costs for each method across the 12 years, expressed as a proportion of the initial investment. These percentages appear in table 4, along with the corresponding cumulative percentage increase in wealth for each method from Figure 3. This shows that the three simple methods have lower transactions costs than the three optimization methods. But it also shows that the cumulative increases in wealth for the three optimization methods are very much larger than for the simple methods, so that the net increases in wealth are much larger for the three optimization methods. This suggests that overall, the three quantitative optimization methods are preferable to the three simple methods after allowing for transactions costs. 


\begin{tabular}{|l|c|c|c|}
\hline & $\begin{array}{l}\text { Total Transactions Costs } \\
\text { as a \% of Initial Wealth }\end{array}$ & $\begin{array}{l}\text { Cumulative \% Increase } \\
\text { in Initial Wealth }\end{array}$ & Differences \\
\hline Markowitz & $5.51 \%$ & $64.92 \%$ & $59.41 \%$ \\
\hline Robust & $5.22 \%$ & $66.13 \%$ & $60.91 \%$ \\
\hline Black-Litterman & $8.82 \%$ & $105.03 \%$ & $96.21 \%$ \\
\hline $1 / \mathrm{N}$ & $2.40 \%$ & $16.95 \%$ & $14.55 \%$ \\
\hline Risk Parity & $2.35 \%$ & $28.61 \%$ & $26.26 \%$ \\
\hline Reward-to-Risk & $3.10 \%$ & $13.66 \%$ & $10.56 \%$ \\
\hline
\end{tabular}

Table 4: Comparison of the cumulative transactions costs and cumulative increases in wealth. Initial investment universe of 100 consistently high performing CSP firms. Estimation period of six years and out-of-sample period of twelve years. $1 / \mathrm{N}$ is the naive diversification approach. 

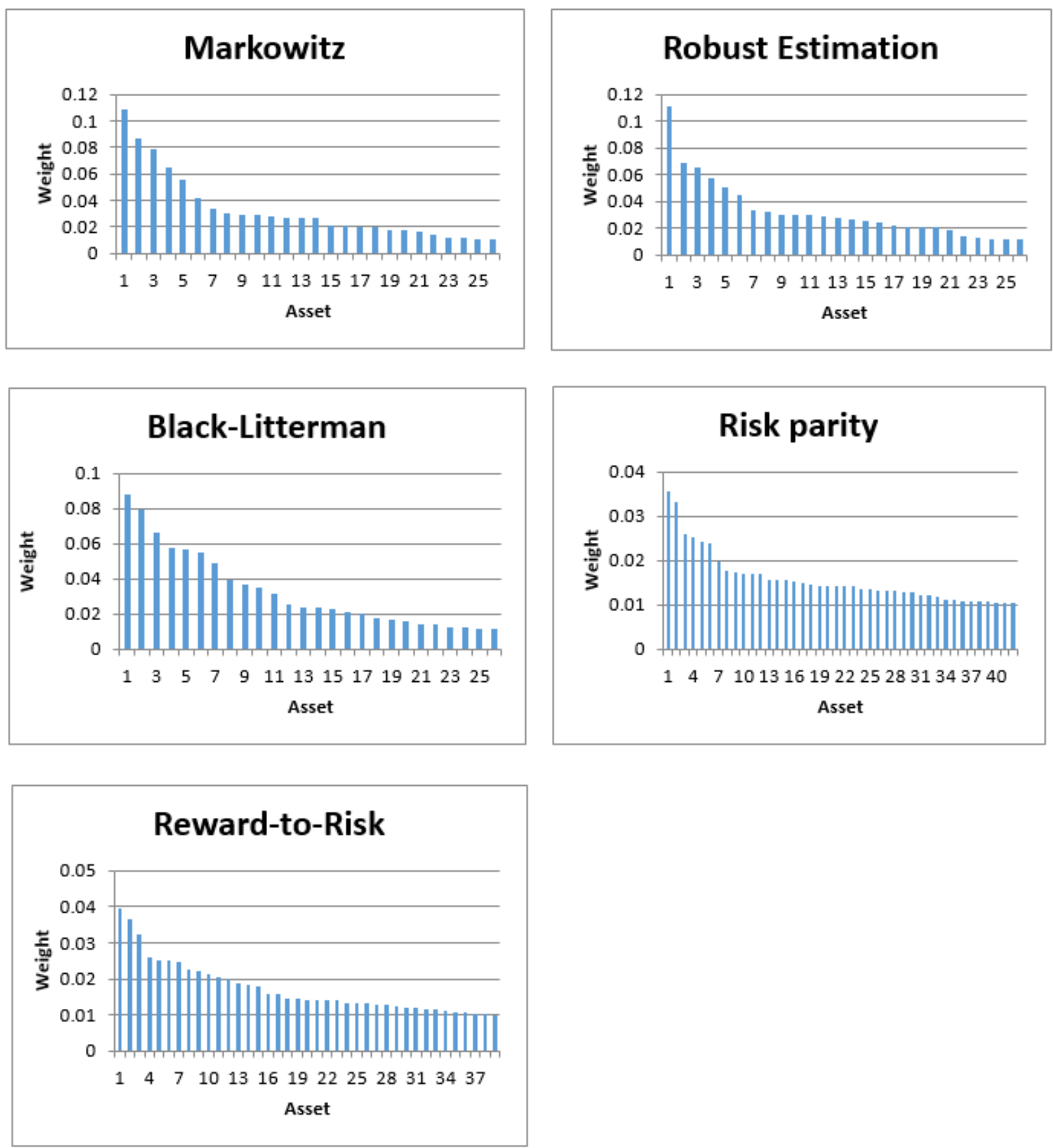

Figure 3: Comparison of the asset weight distributions of SRI portfolios constructed using five different portfolio construction approaches. The vertical axis is the average weight of each asset, and the horizontal axis is the number of the assets concerned, displayed in declining asset weight order. Only weights of assets which are allocated $1 \%$ or more are presented.

Before continuing with the robustness tests and additional analyses, we will compare our key findings with the main conclusions from the general literature on asset allocation. Our results show that, within the SRI framework, the Black-Litterman approach produces portfolios with the strongest out-of-sample risk-adjusted returns. The robust estimation approach generally produces good results, and the reward-to-risk approach beats the naive diversification method, as Kirby and 
Ostdiek (2012) have shown. Our results conflict with those of the general asset allocation literature surveyed above. For an investment universe screened for CSP, the simple methods $(1 / N$, risk parity and reward-to-risk) consistently yield the poorest results in terms of risk, maximum possible losses and risk-adjusted returns; while the sophisticated methods (Black-Litterman, robust estimation and Markowitz) yield the best results. This is an important and interesting finding for the SRI community.

There is additional evidence that the superiority of sophisticated models is greater for portfolios of high SRI companies than for unscreened portfolios. After removing all the firms for which we do not have a complete history of asset returns within the 1991-2012 period, the total sample of unscreened companies is 583 (which is then reduced to 100 by the SRI screening). Table 5 has the results for the full unscreened sample of 583 companies. A comparison with Table 3 shows that screening the companies reduces portfolio risk for both the sophisticated and naive models, and increases returns for the sophisticated models; but reduces returns for the naive models. The result is that the risk-return trade-off for the sophisticated models is improved by SRI screening, but for the naive models SRI screening worsens this trade-off. Hence SRI screening is beneficial when combined with the sophisticated models, but detrimental when combined with the naive models. This is consistent with estimation risk being larger for companies with a high SRI score which is better dealt with by the sophisticated models. 


\begin{tabular}{|l|c|c|c|c|c|c|}
\hline Performance Measures & Markowitz & Robust & $\begin{array}{c}\text { Black- } \\
\text { Litterman }\end{array}$ & $\mathbf{1 / N}$ & $\begin{array}{c}\text { Risk } \\
\text { Parity }\end{array}$ & $\begin{array}{c}\text { Reward } \\
\text {-to-Risk }\end{array}$ \\
\hline Risk Measures & & & & & & \\
\hline Mean standard deviation & 0.1441 & 0.1442 & 0.1442 & 0.2200 & 0.1821 & 0.1750 \\
\hline Mean downside standard deviation & 0.1046 & 0.1047 & 0.1047 & 0.1538 & 0.1321 & 0.1322 \\
\hline VaR (99\%) & 0.1591 & 0.1597 & 0.1602 & 0.2467 & 0.2221 & 0.2414 \\
\hline Conditional VaR (99\%) & 0.1849 & 0.1852 & 0.1856 & 0.2529 & 0.2298 & 0.2446 \\
\hline Maximum Drawdown Rate & 0.3680 & 0.3685 & 0.3671 & 0.5733 & 0.4995 & 0.5406 \\
\hline Risk-Return Trade-Off & & & & & & \\
\hline Mean Risk-Adjusted Returns & 0.3526 & 0.3536 & 0.3632 & 0.1704 & 0.2396 & 0.1654 \\
\hline Dowd Ratio & 0.0266 & 0.0266 & 0.0272 & 0.0127 & 0.0164 & 0.0100 \\
\hline Sortino Ratio & 0.4856 & 0.4868 & 0.5002 & 0.2436 & 0.3302 & 0.2190 \\
\hline Omega Ratio & 1.3285 & 1.3295 & 1.3398 & 1.1499 & 1.2174 & 1.1450 \\
\hline Sterling Ratio & 0.0575 & 0.0575 & 0.0606 & 0.0329 & 0.0418 & 0.0225 \\
\hline Calmar Ratio & 0.0115 & 0.0115 & 0.0119 & 0.0054 & 0.0073 & 0.0045 \\
\hline Burke Ratio & & & & & & \\
\hline Diversification and Stability & 0.0013 & 0.0014 & 0.0008 & 0.0010 & 0.0006 \\
\hline Mean Diversification & & 0.0337 & 0.0323 & 0.0017 & 0.0026 & 0.0043 \\
\hline Mean Stability & & 0.0377 & 0.0379 & 0.0000 & 0.0004 & 0.0026 \\
\hline
\end{tabular}

Table 5: Comparison of the performance of six different portfolio construction approaches across fourteen different metrics. Unscreened sample of 583 firms. Estimation period of six years and out-of-sample period of twelve years. $\mathrm{VaR}$ stands for Value at Risk, and $1 / N$ is the naive diversification approach 


\subsection{Robustness tests}

To test the robustness of our results, we narrow our investment universe to the top 80 firms (a significant shrinkage of $20 \%$ in the number of assets) in terms of aggregate CSP score. According to traditional finance theory, further restricting the investment universe should lead to inferior portfolio performance. On the other hand, given the strong empirical link between higher CSP and lower financial risk (Orlitzky and Benjamin, 2001; Godfrey et al., 2009; Oikonomou et al., 2012), applying more intense CSP screening criteria may improve the performance of SRI portfolios. Hence, we decrease the number of equities to 80 and use the same estimation and investment periods as in our previous analysis to compare the performance of SRI portfolios according to their construction method. The results are summarized in Table 6 .

\begin{tabular}{|l|c|c|c|c|c|c|}
\hline Performance Measures & Markowitz & Robust & $\begin{array}{c}\text { Black- } \\
\text { Litterman }\end{array}$ & 1/N & $\begin{array}{c}\text { Risk } \\
\text { Parity }\end{array}$ & $\begin{array}{c}\text { Reward- } \\
\text { to-Risk }\end{array}$ \\
\hline Risk Measures & & & & & & \\
\hline Mean standard deviation & 0.1281 & 0.1242 & 0.1514 & 0.2135 & 0.1670 & 0.1622 \\
\hline Mean downside standard deviation & 0.0853 & 0.0839 & 0.0933 & 0.1488 & 0.1208 & 0.1229 \\
\hline VaR(99\%) & 0.1180 & 0.1168 & 0.1320 & 0.2438 & 0.2021 & 0.2094 \\
\hline Conditional VaR(99\%) & 0.1389 & 0.1404 & 0.1447 & 0.2487 & 0.2170 & 0.2319 \\
\hline Maximum Drawdown Rate & 0.2879 & 0.2954 & 0.2530 & 0.6493 & 0.5430 & 0.6168 \\
\hline Risk-Return Trade-Off & & & & & & \\
\hline Mean Risk-Adjusted Returns & 0.4631 & 0.4580 & 0.4584 & 0.0890 & 0.1582 & 0.0598 \\
\hline Dowd Ratio & 0.0419 & 0.0406 & 0.0438 & 0.0065 & 0.0109 & 0.0039 \\
\hline Sortino Ratio & 0.6952 & 0.6775 & 0.7439 & 0.1277 & 0.2186 & 0.0789 \\
\hline Omega Ratio & 1.4365 & 1.4229 & 1.3999 & 1.0764 & 1.1395 & 1.0505 \\
\hline Sterling Ratio & 0.1064 & 0.1041 & 0.1162 & 0.0143 & 0.0231 & 0.0063 \\
\hline Calmar Ratio & 0.0172 & 0.0160 & 0.0229 & 0.0024 & 0.0041 & 0.0013 \\
\hline Burke Ratio & 0.0019 & 0.0019 & 0.0022 & 0.0004 & 0.0006 & 0.0002 \\
\hline Diversification and Stability & & & & & & \\
\hline Mean Diversification & 0.1012 & 0.0649 & 0.2312 & 0.0125 & 0.0187 & 0.0301 \\
\hline Mean Stability & 0.0706 & 0.0413 & 0.4892 & 0.0000 & 0.0023 & 0.0190 \\
\hline
\end{tabular}

Table 6: Comparison of the performance of six different portfolio construction approaches across fourteen different metrics. Initial investment universe of 80 consistently high performing CSP firms. Estimation period of six years and out-of-sample period of three years. VaR stands for Value at Risk and $1 / N$ is the naive diversification approach.

The reduction in the number of assets included in the SRI portfolios does not change the core of our previous conclusions. The robust estimation approach still produces the least risky portfolios (having the lowest average standard deviation, downside standard deviation and VaR, and the second lowest conditional $\mathrm{VaR}$ ), with Markowitz usually creating the second best portfolios in this regard, with the Black-Litterman approach following next. At the other end of the spectrum the 
naïve diversification approach leads to the riskiest portfolios, while the risk parity and reward-torisk approaches also have high risk. Compared to the core results, the situation is a bit different for the risk-return metrics, although the traditional, more quantitative optimization methods still outperform the mathematically less formal alternatives. The Black-Litterman technique still ranks first in this dimension according to every metric (except for the Omega ratio). The Markowitz model usually finishes second best, and tends to outperform the robust portfolio. The naive diversification and reward-to-risk portfolios still have the lowest risk-adjusted returns on every relevant metric. As previously, the rank order is reversed when looking at the diversification and stability measures, with the $1 / N$ approach producing the best results, followed by risk parity. The Black-Litterman model finishes last, with Markowitz as second worst. Overall, even when significantly reducing the investment universe, the rank order of the different approaches remains largely unchanged. The sophisticated approaches have lower risk and a superior risk-return tradeoff than the unsophisticated approaches, but the simpler techniques are more diversified and stable.

Since portfolio optimization methods are often sensitive to the estimation period length, see for instance discussions in DeMiguel et al. (2009b), Platanakis and Sutcliffe (2017), and others, as a second robustness test we keep the number of assets (firms) at 100 but change the length of the estimation periods to nine years (108 months) instead of six years ( 72 months). Tables 7 and 8 provide the relevant details of the new estimation and investment periods. We now have only three estimation periods and three investment periods.

\begin{tabular}{c|ccc}
\hline Periods $(\mathrm{t})$ & Start & End & Length \\
\cline { 1 - 1 } Estimation Period 1 & 1994M1 & 2002M12 & 108 \\
\cline { 1 - 1 } Estimation Period 2 & 1997M1 & 2005M12 & 108 \\
\cline { 1 - 1 } Estimation Period 3 & 2000M1 & 2008M12 & 108 \\
\hline
\end{tabular}

Table 7: Nine-Year Estimation Periods

\begin{tabular}{c|ccc}
\hline Periods $(\mathrm{t})$ & Start & End & Length \\
\cline { 1 - 1 } Investment Period 1 & 2003M1 & 2005M12 & 36 \\
\cline { 1 - 1 } Investment Period 2 & $2006 \mathrm{M} 1$ & $2008 \mathrm{M} 12$ & 36 \\
\cline { 1 - 1 } Investment Period 3 & 2009M1 & 2011M12 & 36 \\
\hline
\end{tabular}

Table 8: Non-Overlapping Three-Year Investment Periods 


\begin{tabular}{|l|c|c|c|c|c|c|}
\hline Performance Measures & Markowitz & Robust & $\begin{array}{c}\text { Black- } \\
\text { Litterman }\end{array}$ & $\mathbf{1 / N}$ & $\begin{array}{c}\text { Risk } \\
\text { Parity }\end{array}$ & $\begin{array}{c}\text { Reward- } \\
\text { to-Risk }\end{array}$ \\
\hline Risk Measures & & & & & & \\
\hline Mean standard deviation & 0.1249 & 0.1250 & 0.1247 & 0.2237 & 0.1846 & 0.1619 \\
\hline Mean downside standard deviation & 0.0822 & 0.0826 & 0.0820 & 0.1597 & 0.1345 & 0.1244 \\
\hline VaR(99\%) & 0.1354 & 0.1363 & 0.1346 & 0.2559 & 0.2255 & 0.2318 \\
\hline Conditional VaR(99\%) & 0.1354 & 0.1363 & 0.1346 & 0.2559 & 0.2255 & 0.2318 \\
\hline Maximum Drawdown Rate & 0.2543 & 0.2578 & 0.2519 & 0.6531 & 0.5689 & 0.5483 \\
\hline Risk-Return Trade-Off & & & & & & \\
\hline Mean Risk-Adjusted Returns & 0.4799 & 0.4795 & 0.4840 & 0.0659 & 0.1101 & 0.1272 \\
\hline Dowd Ratio & 0.0369 & 0.0366 & 0.0374 & 0.0048 & 0.0075 & 0.0074 \\
\hline Sortino Ratio & 0.7288 & 0.7253 & 0.7365 & 0.0923 & 0.1511 & 0.1655 \\
\hline Omega Ratio & 1.4492 & 1.4484 & 1.4536 & 1.0565 & 1.0971 & 1.1121 \\
\hline Sterling Ratio & 0.1223 & 0.1204 & 0.1258 & 0.0093 & 0.0144 & 0.0140 \\
\hline Calmar Ratio & 0.0196 & 0.0194 & 0.0200 & 0.0019 & 0.0030 & 0.0031 \\
\hline Burke Ratio & 0.0024 & 0.0024 & 0.0024 & 0.0003 & 0.0005 & 0.0005 \\
\hline Diversification and Stability & & & & & & \\
\hline Mean Diversification & 0.0869 & 0.0798 & 0.0871 & 0.0100 & 0.0150 & 0.0233 \\
\hline Mean Stability & 0.0605 & 0.0542 & 0.0600 & 0.0000 & 0.0009 & 0.0107 \\
\hline
\end{tabular}

Table 9: Comparison of the performance of six different portfolio construction approaches across fourteen different metrics. Initial investment universe of 100 consistently high performing CSP firms. Estimation period of nine years.

The results are summarized in Table 9. All our previous conclusions remain valid, and in some cases are even stronger than those drawn from the original results. The Black-Litterman model dominates all the alternative SRI portfolios according to every metric of risk and risk-adjusted performance. The Markowitz and robust approaches are second and third best respectively according to the same criteria. The naïve diversification technique produces the riskiest portfolios with the worst risk-return ratios, while the risk-parity and reward-to-risk portfolios do not fare much better. Once more, the $1 / N$ approach leads to the most stable and well-diversified portfolios, followed by the risk-parity portfolios; whereas the Markowitz and Black-Litterman portfolios perform worst on both these dimensions.

Lastly, in order to further account for the likely sensitivity of our results to the selection of the length of the estimation and investment (out-of-sample) periods, we form our SRI portfolios by applying the six different portfolio construction approaches but using an estimation period of six years, and an investment period of one year. The results are nearly identical with those of our original analysis. We do not report them here for the sake of brevity but they are available from the authors on request. 


\subsection{Additional analyses}

It has been documented that different measures of CSP based on different aspects or dimensions of corporate sustainability relate to distinct stakeholder groups (Griffin and Mahon, 1997; Mattingly and Berman, 2006) and may have different impacts on financial performance. This is especially relevant when looking at samples of firms from different industries, where the social and environmental issues and key performance indicators can be significantly different. So far in our analysis we avoided this issue by using an aggregate, multidimensional measure of CSP to construct SRI portfolios. In this subsection, we create five different SRI investment data sets, each based on one of the CSP qualitative issue areas from which the aggregate CSP measure was constructed; i.e. relationships with local communities, diversity in the workplace, employee relations, environmental considerations, and product safety and quality.

To construct these SRI portfolios we follow the principles outlined in subsection 4.1. Thus, we use the top 100 firms for each of the qualitative issue areas, and the estimation and investment periods described in Tables 1 and 2. The performance metrics and the optimization approaches employed also remain the same. The results appear in Table 10 which contains five different panels, each of which focuses on one of the five CSP dimensions.

\begin{tabular}{|c|c|c|c|c|c|c|}
\hline Community relations & Markowitz & Robust & $\begin{array}{c}\text { Black- } \\
\text { Litterman }\end{array}$ & $1 / \mathbf{N}$ & $\begin{array}{c}\text { Risk } \\
\text { Parity }\end{array}$ & $\begin{array}{l}\text { Reward- } \\
\text { to-Risk }\end{array}$ \\
\hline Mean standard deviation & 0.1433 & 0.1458 & 0.1649 & 0.2134 & 0.1784 & 0.1605 \\
\hline Mean downside standard deviation & 0.1042 & 0.1063 & 0.1166 & 0.1508 & 0.1332 & 0.1234 \\
\hline $\operatorname{VaR}(99 \%)$ & 0.1939 & 0.1962 & 0.2031 & 0.2387 & 0.2032 & 0.1869 \\
\hline Conditional VaR $(99 \%)$ & 0.1994 & 0.2008 & 0.2132 & 0.2513 & 0.2298 & 0.2168 \\
\hline Maximum Drawdown Rate & 0.3806 & 0.4000 & 0.3742 & 0.6010 & 0.5781 & 0.5811 \\
\hline Mean Risk-Adjusted Returns & 0.3793 & 0.3365 & 0.3945 & 0.1542 & 0.1417 & 0.0995 \\
\hline Dowd Ratio & 0.0234 & 0.0208 & 0.0267 & 0.0115 & 0.0104 & 0.0071 \\
\hline Sortino Ratio & 0.5219 & 0.4615 & 0.5579 & 0.2182 & 0.1899 & 0.1294 \\
\hline Omega Ratio & 1.3680 & 1.3203 & 1.3840 & 1.1368 & 1.1259 & 1.0860 \\
\hline Sterling Ratio & 0.0766 & 0.0617 & 0.0815 & 0.0277 & 0.0200 & 0.0116 \\
\hline Calmar Ratio & 0.0119 & 0.0102 & 0.0145 & 0.0046 & 0.0036 & 0.0023 \\
\hline Burke Ratio & 0.0016 & 0.0013 & 0.0018 & 0.0007 & 0.0005 & 0.0003 \\
\hline Mean Diversification & 0.0805 & 0.0724 & 0.1421 & 0.0100 & 0.0147 & 0.0226 \\
\hline Mean Stability & 0.0741 & 0.0731 & 0.2710 & 0.0000 & 0.0026 & 0.0154 \\
\hline Diversity & Markowitz & Robust & $\begin{array}{c}\text { Black- } \\
\text { Litterman }\end{array}$ & $1 / \mathbf{N}$ & $\begin{array}{c}\text { Risk } \\
\text { Parity }\end{array}$ & $\begin{array}{l}\text { Reward- } \\
\text { to-Risk }\end{array}$ \\
\hline Mean standard deviation & 0.1429 & 0.1437 & 0.1628 & 0.2097 & 0.1648 & 0.1650 \\
\hline Mean downside standard deviation & 0.1023 & 0.1027 & 0.1073 & 0.1482 & 0.1220 & 0.1309 \\
\hline $\operatorname{VaR}(99 \%)$ & 0.1326 & 0.1428 & 0.1487 & 0.2314 & 0.2116 & 0.2293 \\
\hline Conditional $\operatorname{VaR}(99 \%)$ & 0.1491 & 0.1542 & 0.1593 & 0.2453 & 0.2122 & 0.2299 \\
\hline
\end{tabular}




\begin{tabular}{|c|c|c|c|c|c|c|}
\hline Maximum Drawdown Rate & 0.4899 & 0.4966 & 0.3954 & 0.7746 & 0.6642 & 0.8273 \\
\hline Mean Risk-Adjusted Returns & 0.1519 & 0.1501 & 0.2319 & -0.0074 & 0.0257 & -0.1238 \\
\hline Dowd Ratio & 0.0136 & 0.0126 & 0.0211 & -0.0006 & 0.0017 & -0.0074 \\
\hline Sortino Ratio & 0.2123 & 0.2100 & 0.3517 & -0.0104 & 0.0347 & -0.1560 \\
\hline Omega Ratio & 1.1272 & 1.1257 & 1.2043 & 0.9939 & 1.0217 & 0.9003 \\
\hline Sterling Ratio & 0.0169 & 0.0166 & 0.0363 & -0.0009 & 0.0027 & -0.0086 \\
\hline Calmar Ratio & 0.0037 & 0.0036 & 0.0080 & -0.0002 & 0.0005 & -0.0021 \\
\hline Burke Ratio & 0.0005 & 0.0005 & 0.0009 & 0.0000 & 0.0001 & -0.0003 \\
\hline Mean Diversification & 0.0900 & 0.0610 & 0.1071 & 0.0100 & 0.0145 & 0.0244 \\
\hline Mean Stability & 0.0562 & 0.0478 & 0.0999 & 0.0000 & 0.0016 & 0.0149 \\
\hline Employee relations & Markowitz & Robust & \begin{tabular}{|c|} 
Black- \\
Litterman \\
\end{tabular} & $1 / \mathbf{N}$ & $\begin{array}{c}\text { Risk } \\
\text { Parity }\end{array}$ & $\begin{array}{l}\text { Reward- } \\
\text { to-Risk }\end{array}$ \\
\hline Mean standard deviation & 0.1537 & 0.1479 & 0.1475 & 0.2031 & 0.1726 & 0.1722 \\
\hline Mean downside standard deviation & 0.1125 & 0.1088 & 0.1059 & 0.1454 & 0.1276 & 0.1329 \\
\hline $\operatorname{VaR}(99 \%)$ & 0.1371 & 0.1376 & 0.1414 & 0.2141 & 0.1763 & 0.2005 \\
\hline Conditional $\operatorname{VaR}(99 \%)$ & 0.1952 & 0.1933 & 0.1877 & 0.2434 & 0.2215 & 0.2475 \\
\hline Maximum Drawdown Rate & 0.3675 & 0.3719 & 0.3453 & 0.5345 & 0.4713 & 0.5287 \\
\hline Mean Risk-Adjusted Returns & 0.3445 & 0.3499 & 0.3819 & 0.1297 & 0.2078 & 0.1396 \\
\hline Dowd Ratio & 0.0322 & 0.0313 & 0.0332 & 0.0103 & 0.0170 & 0.0100 \\
\hline Sortino Ratio & 0.4710 & 0.4756 & 0.5319 & 0.1812 & 0.2813 & 0.1809 \\
\hline Omega Ratio & 1.3214 & 1.3296 & 1.3568 & 1.1113 & 1.1851 & 1.1223 \\
\hline Sterling Ratio & 0.0576 & 0.0577 & 0.0683 & 0.0205 & 0.0311 & 0.0166 \\
\hline Calmar Ratio & 0.0120 & 0.0116 & 0.0136 & 0.0041 & 0.0063 & 0.0038 \\
\hline Burke Ratio & 0.0013 & 0.0013 & 0.0015 & 0.0006 & 0.0008 & 0.0005 \\
\hline Mean Diversification & 0.0825 & 0.0665 & 0.0803 & 0.0100 & 0.0168 & 0.0267 \\
\hline Mean Stability & 0.0897 & 0.0543 & 0.0816 & 0.0000 & 0.0030 & 0.0166 \\
\hline Environment & Markowitz & Robust & $\begin{array}{c}\text { Black- } \\
\text { Litterman }\end{array}$ & $1 / \mathbf{N}$ & $\begin{array}{c}\text { Risk } \\
\text { Parity }\end{array}$ & $\begin{array}{l}\text { Reward- } \\
\text { to-Risk }\end{array}$ \\
\hline Mean standard deviation & 0.1381 & 0.1376 & 0.1392 & 0.2190 & 0.1699 & 0.1585 \\
\hline Mean downside standard deviation & 0.0997 & 0.1012 & 0.0973 & 0.1511 & 0.1199 & 0.1149 \\
\hline $\operatorname{VaR}(99 \%)$ & 0.1395 & 0.1388 & 0.1444 & 0.2298 & 0.1939 & 0.1792 \\
\hline Conditional $\mathrm{VaR}(99 \%)$ & 0.1504 & 0.1496 & 0.1470 & 0.2306 & 0.1973 & 0.1890 \\
\hline Maximum Drawdown Rate & 0.4469 & 0.4621 & 0.3792 & 0.6466 & 0.5077 & 0.5016 \\
\hline Mean Risk-Adjusted Returns & 0.1752 & 0.1426 & 0.2242 & 0.0592 & 0.1772 & 0.1419 \\
\hline Dowd Ratio & 0.0145 & 0.0118 & 0.0180 & 0.0047 & 0.0129 & 0.0105 \\
\hline Sortino Ratio & 0.2429 & 0.1939 & 0.3205 & 0.0858 & 0.2513 & 0.1958 \\
\hline Omega Ratio & 1.1454 & 1.1169 & 1.1875 & 1.0482 & 1.1531 & 1.1203 \\
\hline Sterling Ratio & 0.0208 & 0.0163 & 0.0307 & 0.0085 & 0.0281 & 0.0168 \\
\hline Calmar Ratio & 0.0045 & 0.0035 & 0.0069 & 0.0017 & 0.0049 & 0.0037 \\
\hline Burke Ratio & 0.0005 & 0.0004 & 0.0007 & 0.0003 & 0.0007 & 0.0005 \\
\hline Mean Diversification & 0.0856 & 0.0790 & 0.0937 & 0.0100 & 0.0149 & 0.0247 \\
\hline Mean Stability & 0.0729 & 0.0752 & 0.1153 & 0.0000 & 0.0017 & 0.0150 \\
\hline Product safety and quality & Markowitz & Robust & $\begin{array}{c}\text { Black- } \\
\text { Litterman }\end{array}$ & $1 / \mathrm{N}$ & $\begin{array}{c}\text { Risk } \\
\text { Parity }\end{array}$ & $\begin{array}{l}\text { Reward- } \\
\text { to-Risk }\end{array}$ \\
\hline Mean standard deviation & 0.1610 & 0.1609 & 0.1938 & 0.2449 & 0.2014 & 0.1931 \\
\hline Mean downside standard deviation & 0.1218 & 0.1242 & 0.1440 & 0.1739 & 0.1490 & 0.1452 \\
\hline
\end{tabular}




\begin{tabular}{|l|c|c|c|c|c|c|} 
VaR $(99 \%)$ & 0.1642 & 0.1675 & 0.2170 & 0.2630 & 0.2418 & 0.2346 \\
\hline Conditional VaR(99\%) & 0.2103 & 0.2217 & 0.2406 & 0.2836 & 0.2741 & 0.2719 \\
\hline Maximum Drawdown Rate & 0.5993 & 0.6195 & 0.8073 & 0.8290 & 0.6744 & 0.6969 \\
\hline Mean Risk-Adjusted Returns & 0.0686 & 0.0662 & -0.1149 & -0.0224 & 0.1141 & 0.0782 \\
\hline Dowd Ratio & 0.0056 & 0.0053 & -0.0086 & -0.0017 & 0.0079 & 0.0054 \\
\hline Sortino Ratio & 0.0907 & 0.0857 & -0.1547 & -0.0316 & 0.1542 & 0.1039 \\
\hline Omega Ratio & 1.0574 & 1.0559 & 0.9109 & 0.9819 & 1.1002 & 1.0662 \\
\hline Sterling Ratio & 0.0067 & 0.0062 & -0.0097 & -0.0028 & 0.0152 & 0.0087 \\
\hline Calmar Ratio & 0.0015 & 0.0014 & -0.0023 & -0.0006 & 0.0028 & 0.0018 \\
\hline Burke Ratio & 0.0002 & 0.0002 & -0.0004 & -0.0001 & 0.0005 & 0.0003 \\
\hline Mean Diversification & 0.0955 & 0.0845 & 0.0983 & 0.0100 & 0.0155 & 0.0254 \\
\hline Mean Stability & 0.0761 & 0.0629 & 0.1346 & 0.0000 & 0.0030 & 0.0154 \\
\hline
\end{tabular}

Table 10: Comparison of the performance of six different portfolio construction approaches across fourteen different metrics for five different dimensions of corporate social and environmental performance. Initial investment universe of 100 consistently high performing CSP firms. Estimation period of six years and out-of-sample period of twelve years. VaR stands for Value at Risk and $1 / N$ is the naive diversification approach.

Table 10 reveals that, although there is variability, the conclusions drawn from the aggregate measure of CSP are verified for the majority of the individual CSP dimensions. More specifically, the Black-Litterman approach consistently produces the highest risk-return trade-offs (and the minimum drawdown rate) for the community relations, diversity and employee relations aspects of CSP. Markowitz also does very well in these CSP dimensions, creating portfolios with the lowest volatility, downside risk and VaR, while also usually finishing second in terms of risk-adjusted returns. The robust approach ranks second or third in terms of both riskiness and risk-return tradeoffs, whereas the naïve diversification and reward-to-risk approaches invariably lead to portfolios with the worst values on these measures. So once again the formal optimization models outperform the less strict portfolio construction approaches. However, in line with the core findings of this study, the $1 / N$ approach still produces the most well-diversified and stable portfolios, while the Black-Litterman and Markowitz models finish last on these criteria.

The picture is qualitatively similar, although not identical, when focusing on corporate environmental performance. The key differences are that the robust portfolio performs less well, finishing next to last on most of the risk-adjusted return ratios, while the risk-parity portfolio does better, being ranked second best on most risk-return metrics. Black-Litterman is still the model of choice according to most criteria, while $1 / N$ is last.

Things are quite different when using product safety and quality as the CSP feature guiding portfolio construction. This is the only CSP dimension where the Black-Litterman approach leads to poorly performing portfolios with the worst risk-adjusted returns, diversification and stability 
characteristics. On the other hand, the risk parity and reward-to-risk techniques are the methods with the best and second best risk-return trade-offs respectively, something that has not been the case in any of our previous analysis.

The distinctiveness of CSP dimensions and the variability of the financial impacts of each has been well documented in the empirical CSP literature (Hillman and Keim, 2001; Mattingly and Berman, 2006; Oikonomou et al., 2012). Hence, our results are compatible with previous findings. Overall, Table 9 shows that the results from the solo use of the CSP measures produces only slightly different conclusions. This suggests that our results are not highly sensitive to the weighting scheme involved in computing the aggregate CSP.

\section{Discussion}

Before providing the concluding remarks of our paper, it is worth reflecting on the practical implications our findings have for the finance industry and the business world as a whole. Professional fund managers, corporations, regulators and activists are all potentially influenced by the repercussions of our study.

In a nutshell, our research clearly shows that the optimization process matters within the framework of Socially Responsible Investing, thus supporting our first hypothesis. Hence, all SRI fund managers should consider not only the type of "responsible" screening criteria they use to narrow their investment universe, but also the technique they employ in order to identify the optimal investment weights. From the viewpoint of modern portfolio theory this finding is expected. What comes as more of a surprise is that our findings strongly support hypothesis 2 and the use of more quantitatively sophisticated optimization techniques, rather than naïve/simplistic techniques. This conclusion is the opposite of what most of the mainstream finance literature advocates, and may be due to the additional estimation risk caused by the inherent "noise" in CSP scores. Regardless of the reason, the key point is that sophisticated quantitative optimization methods can help SRI investors maximize their wealth on a risk-adjusted basis, even after accounting for transaction costs.

The implications of this observation have direct and profound effects for the investment world. A multitude of professional asset managers, including mutual funds, closed-end funds, hedge funds and other pooled investment vehicles, have invested more than $\$ 8$ trillion in the US alone, with the number of SRI funds and their assets under management growing at a much higher pace than 
the industry as a whole ${ }^{12}$. One of the major deterrents to SRI becoming more mainstream and appealing to an even greater pool of potential investors has been that SRI strategies "prioritise qualitative research and (involve) a lot of subjective judgment" (Grene, 2016). This criticism would be significantly alleviated by the introduction and/or more widespread use of well-known, quantitatively rigorous optimization techniques. Investors who believe that SRI is too "soft", qualitative and subjective on the methods it uses may be convinced otherwise with the introduction of formal optimization techniques in the field and consider putting their money in SRI funds. Similarly, both institutional and retail investors who do not use intermediaries, would benefit from the application of such methods when constructing their portfolios.

This additional inflow of funds to the SRI industry arising from using appropriate quantitative optimization methods will also have indirect - albeit important-consequences for a broader range of constituents. Most notably, responsible businesses should be primary beneficiaries of this change as it will increase the demand for their shares, lower their cost of capital and allow them to invest in more positive net present value projects. This more efficient capital allocation will lead to higher growth rates for such firms, while the exact opposite is likely to happen to irresponsible corporations. It is also worth pointing out that these effects are likely to be more pronounced for the largest and most visible firms, as the market tends to respond more to CSP information for firms with such corporate characteristics (Brammer and Millington, 2008; Zyglidopoulos et al., 2012). Similarly, given that multinational enterprises (MNEs) are likely to respond more to pressure from salient stakeholders to improve their CSP (Husted and Allen, 2006), the additional funds that will accrue to high socially performing MNEs, and away from their low performing counterparts, will give them an increased competitive advantage.

Stakeholders who are interested in increasing the positive environmental and social externalities of businesses would also be happy with the above development. More capital will be in the hands of firms who support CSP, allowing charitable foundations, environmental activists, various pressure groups and NGOs to lobby these firms to increase their CSP activities. This will increase social and environmental benefits.

Finally, financial regulators should benefit from increased investment in firms with high CSP scores. The empirical literature on the financial effects of CSP provides ample evidence that a

\footnotetext{
${ }^{12}$ Report on US Sustainable, Responsible and Impact Investing Trends 2016. Summary available at: http://www.ussif.org/files/SIF_Trends_16_Executive_Summary(1).pdf
} 
higher level of CSP is associated with lower systematic and idiosyncratic risk (Luo and Bhattacharya, 2009; Orlitzky and Benjamin, 2001; Oikonomou, Brooks, and Pavelin, 2012). Hence, more investment in high CSP performers should contribute to a less volatile investment environment and a less frequent occurrence of substantial financial crises.

\section{Conclusions}

We expand the SRI literature by moving beyond the question of whether portfolios comprising "sustainable equities" outperform conventional investments, and focus on finding optimal ways to construct SRI portfolios. We argue that SRI portfolios are characterised by a greater level of uncertainty compared to their conventional counterparts because of the added complexity in measuring CSP, and the discretionary nature of sustainability reporting. Due to this, we expect that SRI portfolios are associated with higher levels of estimation risk. This has a direct impact on the inputs of optimization models, and can lead to different techniques being preferable to those used to form portfolios of conventional assets.

We have found that the optimization process for forming SRI portfolios matters. There are large, economically significant differences in the risk, risk-adjusted returns, diversification and intertemporal stability of the SRI portfolios, depending on which optimization technique is used. Formal optimization techniques (Markowitz, Black-Litterman and robust estimation) tend to produce less risky SRI portfolios with higher risk-adjusted returns and a smaller total number of constituent assets compared to less formal techniques (naïve diversification, risk parity and rewardto-risk). The Black-Litterman model is usually the best technique, while naïve diversification is usually the worst on these criteria. These conclusions are robust to different lengths of the estimation and investment periods, and to the use of more stringent CSP screening criteria. Our conclusions using CSP-screened assets are in contrast to studies of unscreened assets, which have found that naive diversification is one of the best techniques. Additional comparative analysis reveals that these conclusions are much stronger for SRI portfolios compared to those produced from an unscreened sample of stocks. This is consistent with SRI portfolios having higher estimation risk which is better addressed by sophisticated portfolio models

When implementing the various portfolio construction approaches for single CSP dimensions, we have found that our key findings for aggregate CSP scores also hold for the community, diversity and employee relations dimensions of CSP. But they are less applicable for environmental performance and product safety and quality. This is in line with previous work in the wider 
literature on the financial effects of CSP, and demonstrates the contextualization required for an analysis to be complete.

Overall, our study shows that just applying stringent SRI criteria to restrict the investment universe to the best socially and environmentally performing companies is insufficient. The optimization process is also very important. It further demonstrates to fund managers, institutional and retail investors (especially those who are more risk-averse and have longer-term investment horizons) that the more quantitative approaches to portfolio construction typically lead to better results. The appropriate selection of an optimization technique is an issue which needs to be taken into serious consideration for anyone placing their funds in SRI. Choosing the correct optimization method for the creation of SRI portfolios will lead to stronger financial performance, which in turn will generate greater demand for this kind of investment. Through this mechanism, the cost of equity for any corporation that applies sustainable/ responsible/ethical practices will be reduced, incentivising them to engage in such behaviour; while penalizing companies involved in various social or environmental controversies by increasing their cost of capital. In short, the selection of the most suitable optimization method for SRI portfolios will have an effect on the bottom line of companies and, through this, on the promotion of societal well-being and environmental conservation. Hence, the results of this study are of interest and importance to a variety of constituents including investors, fund managers, corporate executives, social and environmental activists and overall concerned citizens.

Although our study is innovative within the SRI field, it is limited in the geographic coverage of the markets considered (US). Other CSP datasets, covering different markets, should be used to extend our analysis in this direction. Furthermore, the selection of the CSP criteria and dataset used is always an important issue within the literature (Griffin and Mahon, 1997). Using different social and environmental sources of data and alternative CSP metrics would provide a useful test for the reliability of different optimization methods for SRI. Lastly, our work focuses solely in one assets class (equity). With green bonds on the rise, there is an opportunity to extend our analysis by including fixed income instruments in the SRI portfolios. 


\section{References}

Abbott, W. F. and Monsen R. J. (1979). On the measurement of corporate social responsibility: Self-reported disclosures as a method of measuring corporate social involvement. Academy of Management Journal: vol. 22, pp. 501-515.

Alexander, G.J. (2009) From Markowitz to Modern Risk Management, The European Journal of Finance, vol. 15, no. 5-6, pp. 451-461.

Anderson, R.M., Bianchi, S.W. and Goldberg, L.R. (2012). Will My Risk Parity Strategy Outperform?, Financial Analysts Journal, vol. 68, no. 6, pp. 75-93.

Ang, A. (2014) Asset Management-A Systematic Approach to Factor Investing, Oxford University Press.

Bacon, C., Practical portfolio performance measurement and attribution, 2nd edition, Wiley 2008.

Baker, M., Bradley B. and Wurgler, J. (2011). Benchmarks as Limits to Arbitrage: Understanding the Low Volatility Anomaly, Financial Analysts Journal, vol. 67, pp. 40-54.

Ballestero, E., Bravo, M., Pérez-Gladish, B., Arenas-Parra, M., and Plà-Santamaria, D. (2012) Socially Responsible Investment: A Multicriteria Approach to Portfolio Selection Combining Ethical and Financial Objectives. European Journal of Operational Research, vol. 216, pp. 487-494.

Barnett, M. L. and Salomon, R. M. (2006). Beyond dichotomy: The Curvilinear Relationship between Social Responsibility and Financial Performance, Strategic Management Journal vol. 27, pp. 1101-1122.

Barney, J. B. and Hansen, M.H. (1994) Trustworthiness as a Source of Competitive Advantage, Strategic Management Journal, vol. 15, Winter, pp. 175-190

Barroso, P. (2015) Using Out-of-Sample Errors in Portfolio Optimization, Working paper, University of New South Wales

Becker, F., Gürtler, M. and Hibbeln, M. (2015) Markowitz versus Michaud: Portfolio Optimization Strategies Reconsidered, The European Journal of Finance, vol. 21, no. 4, pp. 269-291.

Berkelaar, A. and Kouwenberg, R (2010). A Liability-Relative Drawdown Approach to Pension Asset Liability Management. Journal of Asset Management, vol. 11, pp. 194-217.

Bernardi, C. and A.W Stark, (forthcoming) Environmental, social and governance disclosure, integrated reporting, and the accuracy of analyst forecasts. The British Accounting Review.

Bessler, W., Opfer H. and Wolff, D. (2017) Multi-Asset Portfolio Optimization and Out-ofSample Performance: An Evaluation of Black-Litterman, Mean-Variance, and Naïve Diversification Approaches, The European Journal of Finance, vol. 23, no. 1, pp. 1-30.

Black, F. and Litterman, R. (1992). Global Portfolio Optimization, Financial Analysts Journal, vol. 48 , no. 5 , pp. $28-43$.

Bloomfield, T., Leftwich, R. and Long, J.B. (1977). Portfolio Strategies and Performance. Journal of Financial Economics vol. 5, pp.201-218. 
Blume, M.E. and Friend, I. (1975) The Asset Structure of Individual Portfolios and Some Implications for Utility Functions, Journal of Finance, vol. 30, pp. 585-603.

Board, J.L.G. and Sutcliffe, C.M.S. (1995) Estimation Methods in Portfolio Selection and the Effectiveness of Short Sales Restrictions: UK Evidence, Management Science, Vol. 40, No. 4, April, pp. 516-534.

Boender, C.G.E. (1997) A Hybrid Simulation-Optimization Scenario Model for Asset-Liability Management, European Journal of Operations Research, vol. 99, pp. 126-135.

Bondell, H.D. and Reich, B.J. (2008) Simultaneous regression shrinkage, variable selection, and supervised clustering of predictors with OSCAR, Biometrics, vol. 64, pp. 115-123.

Bouslah, K., Kryzanowski, L. and M'Zali, B. (2013), The impact of the dimensions of social performance on firm risk, Journal of Banking \& Finance, vol. 37, pp. 1258-1273.

Brammer, S., C. Brooks and S. Pavelin (2006). Corporate social performance and stock returns: UK evidence from disaggregate measures. Financial Management, vol. 35, pp. 97-116.

Brammer, Stephen, and Andrew Millington. 2008. "Does It Pay to Be Different? An Analysis of the Relationship between Corporate Social and Financial Performance." Strategic Management Journal 29 (12): 1325-1343.

Broadie, M. (1993) Computing Efficient Frontiers Using Estimated Parameters, Annals of Operations Research, vol. 45, pp. 21-58.

Brodie, J.I., Daubechies, C.D., Giannone, M.D. and Loris, I. (2008) Sparse and Stable Markowitz Portfolios, European Central Bank. Working Paper Series, no. 936.

Burke. G. (1994). A sharper Sharpe ratio. Futures, vol. 23, no. 3, p. 56.

Capelle-Blancard, G. and Monjon, S. (2014), The Performance of Socially Responsible Funds: Does the Screening Process Matter?. European Financial Management, vol. 20, pp. 494-520.

Carroll, A. B. (1991). The pyramid of corporate social responsibility: Toward the moral management of organizational stakeholders. Business Horizons vol. 34, pp. 39-48.

Chaves, D., Hsu, J., Li, F. and Shakernia, O. (2011) Risk Parity Portfolio vs. Other Asset Allocation Heuristic Portfolios, Journal of Investing, vol. 20, no. 1, Spring, pp. 108-118.

Clarkson, M. B. E. (1995). A stakeholder framework for analysing and evaluating corporate social performance. Academy of Management Review, vol. 20, pp. 92-117.

Cox, P., Brammer, S. and Millington, A. (2004). An empirical examination of institutional investor preferences for corporate social performance. Journal of Business Ethics, vol. 52, pp. 27-43.

Deng, X., Kang, J. K. \& Low, B. S. (2013). Corporate social responsibility and stakeholder value maximization: Evidence from mergers. Journal of Financial Economics, vol. 110, pp. 87-109. 
DeMiguel, V., Garlappi, L., Nogales, F.J. and Uppal, R. (2009a) A Generalized Approach to Portfolio Optimization: Improving Performance by Constraining Portfolio Norms, Management Science, vol. 22, no. 5, pp. 1915-1953.

DeMiguel, V., Garlappi, L. and Uppal, R. (2009b) Optimal Versus Naive diversification: How Inefficient is the $1 / \mathrm{N}$ Portfolio Strategy? The Review of Financial Studies, vol. 22, no. 5, pp. 19151953.

Derwall, J. and K. Koedijk (2009). Socially Responsible Fixed Income Funds. Journal of Business Finance \& Accounting, vol. 36, pp. 210-229.

Di Giuli, Alberta, and Leonard Kostovetsky. 2014. "Are Red or Blue Companies More Likely to Go Green? Politics and Corporate Social Responsibility." Journal of Financial Economics 111 (1): 158-180.

Dowd, K. (2000). Adjusting for Risk: An Improved Sharpe Ratio. International Review of Economics and Finance, vol. 9, pp.209-222.

Drut, B. (2012) Social Responsibility and Mean-Variance Portfolio Selection, Amundi Working Paper.

Duchin, R. and Levy, H. (2009) Markowitz Versus the Talmudic Portfolio Diversification Strategies, Journal of Portfolio Management, vol. 35, no. 2, Winter, pp. 71-74.

Edmans, A. (2011). Does the stock market fully value intangibles? Employee satisfaction and equity prices. Journal of Financial Economics vol. 101, pp. 621-640.

Edwards, M. (2008). Small change: Why business won't save the world. San Francisco: BerrettKoehler.

Eling, M. and Schuhmacher, F. (2007). Does the Choice of Performance Measure Influence the Evaluation of Hedge Funds?, Journal of Banking and Finance, vol. 31, no. 9, pp. 2632-2647.

Elton, E.J. and Gruber, M.J. (1977) Risk Reduction and Portfolio Size, Journal of Business, vol. 50, no. 4, October, pp. 415-437.

Entine, Jon. 2003. "The Myth of Social Investing: A Critique of Its Practice and Consequences for Corporate Social Performance Research.” Organization \& Environment 16 (3): 352-368.

Fan, J., Zhang, J. and Yu, K. (2008) Asset allocation and risk assessment with gross exposure constraints for vast portfolios, The Annals of Statistics, vol. 25, pp. 1425-1432.

Fan, J., Zhang, J. and Yu, K. (2012) Vast Portfolio Selection with Gross-Exposure Constraints, Journal of the American Statistical Association, vol. 107, pp. 592-606.

Fischer, M. and Gallmeyer, M.F. (2016) Heuristic Portfolio Trading Rules with Capital Gain Taxes, Journal of Financial Economics, vol. 119, no. 3, pp. 611-625.

Frazzini, A. and Pedersen, L.H. (2014). Betting Against Beta, Journal of Financial Economics, vol. 111, no. 1, pp. 1-25. 
Galema, R., A. Plantinga and B. Scholtens (2008). The stocks at stake: Return and risk in socially responsible investment. Journal of Banking \& Finance, vol. 32, pp. 2646-2654.

Geyer, A. and Ziemba, W.T. (2008) The Innovest Austrian Pension Fund Financial Planning Model InnoALM, Operations Research, vol. 56, pp. 797-810.

Godfrey, P. C., Merrill, C. B. and Hansen, J.M. (2009). The relationship between corporate social responsibility and shareholder value: an empirical test of the risk management hypothesis. Strategic Management Journal, vol. 30, pp. 425-445.

Gofman, M. and Manela, A. (2012). An Empirical Evaluation of the Black-Litterman Approach to Portfolio Choice. Available at SSRN: http://ssrn.com/abstract=1782033

Goldfarb, D. and Iyengar, G. (2003) Robust Portfolio Selection Problems, Mathematics of Operations Research, vol. 28, no. 1, pp. 1-38.

Green, R. and Hollifield, B. (1992) When will Mean-Variance Efficient Portfolios be well Diversified?, Journal of Finance, vol. 47, no. 5, pp. 1785-1809.

Grene, Sophia. 2016. "Quants Are the New Ethical Investors." Financial Times. https://www.ft.com/content/35798046-a33c-11e5-8d70-42b68cfae6e4.

Griffin, J. J. and. Mahon, J. F (1997). The corporate social performance and corporate financial performance debate. Business \& Society, vol. 36, pp. 5-31.

Hallerbach, W., Ning, H., Soppe, A., and Spronk, J. (2004) A framework for managing a portfolio of socially responsible investments. European Journal of Operational Research, vol. 153, pp. 517-529.

Harjoto, Maretno, Hoje Jo, and Yongtae Kim. 2015. "Is Institutional Ownership Related to Corporate Social Responsibility? The Nonlinear Relation and Its Implication for Stock Return Volatility." Journal of Business Ethics. doi:10.1007/s10551-015-2883-y.

Jacobs, H., Muller, S. and Weber, M. (2014) How Should Individual Investors Diversify? An Empirical Evaluation of Alternative Asset Allocation Policies, Journal of Financial Markets, vol. 19, June, pp. 62-86.

Jagannathan, R. and Ma, T. (2003) Risk Reduction in Large Portfolios: Why Imposing the Wrong Constraints Helps, Journal of Finance, vol. 58, no. 4, August, pp. 1651-1683.

Jo, H., and M. Harjoto. (2012). The causal effect of corporate governance on corporate social responsibility. Journal of Business Ethics, vol. 106, pp. 53-72.

Jorion, P. (1991) Bayesian and CAPM Estimators of the Means: Implications for Portfolio Selection, Journal of Banking and Finance, vol. 15, no. 3, June, pp. 717-727.

Hillman, A. J. and G. D. Keim (2001). Shareholder value, stakeholder management, and social issues: what's the bottom line? Strategic Management Journal, vol. 22, pp. 125-139.

Husted, Bryan W., and David B. Allen. 2006. "Corporate Social Responsibility in the Multinational Enterprise: Strategic and Institutional Approaches.” Journal of International Business Studies 37 (6): 838-849. 
Kan, R., Wang, X. and Zhou, G. (2016) Optimal Portfolio Selection With and Without Risk-Free Asset, Working paper, University of Toronto.

Kaplan, P.D. (2014), Back to Markowitz. Morningstar Indexes 2014/15 Yearbook. Available at: http:/ / corporate.morningstar.com/us/asp/detail.aspx?xmlfile $=8383 . x \mathrm{ml}$

Kempf, A. and P. Osthoff (2007). The effect of socially responsible investing on portfolio performance. European Financial Management, vol. 13, pp. 908-922.

Kempf, A. and Osthoff, P. (2008), SRI Funds: Nomen est Omen. Journal of Business Finance \& Accounting, vol. 35, pp. 1276-1294.

Kirby, C. and Ostdiek B. (2012). It's All in the Timing: Simple Active Portfolio Strategies that Outperform Naive Diversification, Journal of Financial and Quantitative Analysis, vol. 47, no. 2, pp. 437-467.

Krüger, Philipp. 2015. "Corporate Goodness and Shareholder Wealth." Journal of Financial Economics 115 (2): 304-329.

Ledoit, O. and Wolf, M. (2003) Improved Estimation of the Covariance Matrix of Stock Returns with an Application to Portfolio Selection, Journal of Empirical Finance, vol. 10, December, pp. 603621.

Ledoit, O., Wolf, M. (2004) A Well-Conditioned Estimator for Large-Dimensional Covariance Matrices. Journal of Multivariate Analysis, vol. 88, February, pp. 365-411.

Lee, D. D. and Faff, R. W. (2009), Corporate Sustainability Performance and Idiosyncratic Risk: A Global Perspective. Financial Review, vol. 44, pp. 213-237.

Luo, Xueming, and Chitra Bhanu Bhattacharya. 2009. "The Debate over Doing Good: Corporate Social Performance, Strategic Marketing Levers, and Firm-Idiosyncratic Risk." Journal of Marketing 73 (6): 198-213.

Lynn, M. (1992). A note on corporate social disclosure in Hong Kong. The British Accounting Review, 24(2), 105-110.

Margolis, J. D. and J. P. Walsh (2003). Misery loves companies: Rethinking social initiatives by business. Administrative Science Quarterly, vol. 48, pp. 268-305.

Margolis, J., Elfenbein, H., \& Walsh, J. P. (2009). Does it pay to be good and does it matter? A meta-analysis of the relationship between corporate social and financial performance. Harvard Business School Working Paper No. 229.

Markowitz, H. (1952). Portfolio Selection, Journal of Finance, vol. 7, no. 1, pp. 77-91.

Markowitz, H. (1991). Portfolio selection: Efficient diversification of investment (2e). Malden, MA: Blackwell Publishers Inc.

Mattingly, J. E. and Berman, S. L. (2006). Measurement of corporate social action. Business \& Society, vol. 45, pp. 20-46. 
Meucci, A. (2010) The Black-Litterman Approach: Original Model and Extensions, The Encyclopedia of Quantitative Finance, Wiley.

Michaud, R. (1999) Efficient Asset Management: A Practical Guide to Stock Portfolio Optimization and Asset Allocation, Harvard Business School Press.

Oikonomou, I., Brooks, C., \& Pavelin, S. (2012). The impact of corporate social performance on financial risk and utility: A longitudinal analysis. Financial Management, vol. 41, pp. 483-515.

Oikonomou, I., Brooks, C. and Pavelin, S. (2014), The Effects of Corporate Social Performance on the Cost of Corporate Debt and Credit Ratings. Financial Review, vol. 49: pp. 49-75.

Orlitzky, M. and J. D. Benjamin (2001). Corporate social performance and firm risk: A metaanalytic review. Business \& Society, vol. 40, pp. 369-396.

Orlitzky, M., F. L. Schmidt and S.L. Rynes (2003). Corporate social and financial performance: A meta-analysis. Organization Studies, vol. 24, pp. 403-441.

Orlitzky, M. (2013). Corporate social responsibility, noise and stock market volatility, The Academy of Management Perspectives, vol. 27, pp. 238-254.

Pflug, G.C., Pichler, A. and Wozabal, D. (2012) The 1/N Investment Strategy is Optimal Under High Model Ambiguity, Journal of Banking and Finance, vol. 36, no. 2, February, pp. 410-417.

Platanakis, E and Sutcliffe, C. (2017) Asset-Liability Modelling and Pension Schemes: The Application of Robust Optimization to USS, The European Journal of Finance, vol. 23, No. 4, 2017, pp. 324-352.

Qiu, Y., A. Shaukat, and R. Tharyan (2016). "Environmental and social disclosures: Link with corporate financial performance." The British Accounting Review, vol. 48 (1), pp. 102-116.

Renneboog, L., J. Ter Horst, and C. Zhang (2008). The Price of Ethics and Stakeholder Governance: The Performance of Socially Responsible Mutual Funds, Journal of Corporate Finance $14,302-322$.

Rollinger, T. and Hoffman, S (2014). Sortino: A “Sharper” Ratio. Red Rock Capital. http://www.redrockcapital.com/Sortino__A_Sharper_Ratio_Red_Rock_Capital.pdf

Rudolf, M. and Ziemba, W.T. (2004) Intertemporal Surplus Management, Journal of Economic Dynamics and Control, vol. 28, pp. 975-990.

Ryan, L. V. and M. Schneider: 2002, 'The Antecedents of Institutional Investor Activism', Academy of Management Review vol. 27(4), pp. 554-573.

Satchell, S. and Scowcroft, A. (2000) A Demystifcation of the Black-Litterman Model: Managing Quantitative and Traditional Portfolio Construction, Journal of Asset Management, vol. 1, no. 2, pp. 138-150.

Schroder, M. (2007). Is there a difference? The performance characteristics of SRI equity indices. Journal of Business Finance and Accounting, vol. 34, pp. 331-348.

Shadwick, W. and Keating, C. (2002). A universal performance measure Journal of Performance Measurement, vol. 6, no. 3, pp. 59-84. 
Sharfman, M. (1996). The construct validity of the Kinder, Lydenberg \& Domini social performance ratings data. Journal of Business Ethics, vol. 15, pp. 287-296.

Sharpe, W. (1994). The Sharpe Ratio. Journal of Portfolio Management 21, no. 1, pp. 49-59.

Statman, M. (1987) How Many Stocks Make a Diversified Portfolio?, Journal of Financial and Quantitative Analysis, vol. 22, no. 3, September, pp. 353-363.

Statman, M. (2000). Socially responsible mutual funds. Financial Analysts Journal, vol. 56, pp.: 3039.

Statman, M. (2006). Socially responsible indexes. Journal of portfolio Management, vol. 32, pp.: 100109.

Utz, S., Wimmer, M., Hirschberger, M. and Steuer, R.E. (2014) Tri-Criterion Inverse Portfolio Optimization with Application to Socially Responsible Mutual Funds, European Journal of Operational Research, vol. 234, pp. 491-498.

Von Arx, U., \& Ziegler, A. (2014). The effect of corporate social responsibility on stock performance: New evidence for the USA and Europe. Quantitative Finance, vol. 14, pp. 977-991.

Votaw, D. (1973). Genius becomes rare. The Corporate Dilemma-Traditional Values versus Contemporary Problems. Prentice Hall, Englewood Cliffs, NJ.

Waddock, S.A. (2003). Myths and Realities of Social Investing, Organization and Environment, vol. 16, pp. 369-380.

Waddock, S. A. and S. B. Graves: 1997, 'The Corporate Social Performance-Financial Performance Link', Strategic Management Journal vol. 18(4), 303-319.

Windcliff, H. and Boyle, P.P. (2004) The 1/N Pension Investment Puzzle, North American Actuarial Journal, vol. 8, no. 3, July, pp. 32-45.

Wood, D. J. and Jones, R. E. (1995). Stakeholder mismatching: A theoretical problem in empirical research on corporate social performance. International Journal of Organizational Analysis vol. 3, pp. 229-267.

Xing, X., Hu, J. and Yang, Y. (2014) Robust Minimum Variance with L-Infinity Constraints, Journal of Banking and Finance, vol. 46, pp. 107-117.

Young, T. W. (1991). "Calmar Ratio: A Smoother Tool", Futures, vol.20, p.40.

Zhu, L.L. (2015) The Performance of Asset Allocation Strategies Across Datasets and Over Time, Working paper, University of Edinburgh Business School, August, 42 pages.

Ziemba, W.T. and Mulvey, J.M. (1998) Worldwide Asset and Liability Modelling, Cambridge University Press.

Zyglidopoulos, Stelios C., Andreas P. Georgiadis, Craig E. Carroll, and Donald S. Siegel. 2012. "Does Media Attention Drive Corporate Social Responsibility?” Journal of Business Research 65 (11): 1622-1627. 


\section{Appendix A: Mathematical definition of implemented optimization approaches}

\section{Markowitz portfolio optimization}

The optimization framework proposed by Markowitz (1952) assumes that the expected value $(\boldsymbol{\mu})$ and the covariance $(\Sigma)$ of asset returns are known with certainty. Specifically, if $\boldsymbol{\Phi}$ denotes the column vector of portfolio weights (decision variables) defined as $\Phi=\left[\Phi_{1}, \Phi_{2}, \ldots, \Phi_{\mathrm{N}}\right]^{\mathrm{T}}$ with $\mathrm{N}$ assets in the portfolio, a sample variance-covariance matrix of asset returns $(\boldsymbol{\Sigma})$ and a column vector of mean asset returns $\left(\boldsymbol{\mu}=\left[\mu_{1}, \mu_{2}, \ldots, \mu_{\mathrm{N}}\right]^{\mathrm{T}}\right)$, then the minimum variance portfolio selection problem is expressed as follows:

$$
\begin{array}{cl}
\min _{\boldsymbol{\Phi}} & \boldsymbol{\Phi}^{\mathrm{T}} \boldsymbol{\Sigma} \boldsymbol{\Phi} \\
\text { s.t. } & \boldsymbol{\mu}^{\mathrm{T}} \boldsymbol{\Phi} \geq \alpha \\
& \mathbf{1}^{\mathrm{T}} \boldsymbol{\Phi}=1 \\
& \Phi_{\mathrm{i}} \geq 0, \quad \forall \mathrm{i}=1, \ldots, \mathrm{N}
\end{array}
$$

where the objective is the selection of a portfolio $\Phi$ that minimizes the risk (variance) among all feasible portfolios. The constraint $\mathbf{1}^{\mathrm{T}} \boldsymbol{\Phi}=1$ requires that the portfolio weights sum to one. The constraint $\boldsymbol{\mu}^{\mathrm{T}} \boldsymbol{\Phi} \geq \alpha$ sets a lower bound on portfolio mean return. ${ }^{13}$ We also rule out short selling by imposing non-negativity constraints $\left(\Phi_{i} \geq 0\right)$ on the asset weights.

\section{Robust estimation approach}

To deal with the effects of parameter uncertainty we also apply a robust estimation strategy which is inspired by previous studies of robust asset allocation with norm constraints on the portfolio weights, such as DeMiguel et al. (2009a). Specifically, we follow Xing et al. (2014) and impose a constraint of an $\boldsymbol{l}_{\mathbf{1}}$ norm, $\|\boldsymbol{\Phi}\|_{1}$ (taxicab or Manhattan norm) and an $l_{\infty}$ norm, $\|\boldsymbol{\Phi}\|_{\infty}$ (maximum norm) on the portfolio weights. The taxicab norm $\left(l_{l}\right)$ is the sum of the absolute values of a vector,

\footnotetext{
${ }^{13}$ In our analysis, we set the lower bound of the mean portfolio return (parameter $\alpha$ ) to $1 \%$ on an annual basis. We assume this is the minimum expected return an investor would be willing to accept in order to invest in a risky portfolio. The selection of the exact value of $\alpha$ is not crucial in this framework and does not influence the conclusions drawn from our results.
} 
and setting an upper bound on $l_{1}$ encourages sparse solutions, i.e. portfolios with active positions in only a few assets (sparse portfolios), see for instance Brodie et al. (2008).

Having active positions in only a few assets leads to the significant practical benefit of lower transaction costs. However, after applying the $\boldsymbol{l}_{\mathbf{1}}$ norm constraint, some of the positions may be very large. The additional use of the $l_{\infty}$ norm addresses this issue, see for instance Bondell and Reich (2008). The maximum norm $\left(l_{\infty}\right)$ of a vector is the largest absolute value of the elements in the vector, and an upper bound on $l_{\infty}$ prevents large positions in any asset. Therefore a combination of the $\boldsymbol{l}_{\mathbf{1}}$ and $\boldsymbol{l}_{\infty}$ upper bounds tends to produce sparse portfolios without very large individual weights.

By additionally employing the three optimization constraints of problem (1), the optimization problem can be written as follows:

$$
\begin{array}{ll}
\min _{\boldsymbol{\Phi}} & \boldsymbol{\Phi}^{\mathrm{T}} \boldsymbol{\Sigma} \boldsymbol{\Phi} \\
\text { s.t. } & \|\boldsymbol{\Phi}\|_{1}+\|\boldsymbol{\Phi}\|_{\infty} \leq \mathrm{c} \\
& \boldsymbol{\mu}^{\mathrm{T}} \boldsymbol{\Phi} \geq \alpha \\
& \mathbf{1}^{\mathrm{T}} \boldsymbol{\Phi}=1 \\
& \Phi_{\mathrm{i}} \geq 0, \quad \forall \mathrm{i}=1, \ldots, \mathrm{N}
\end{array}
$$

where $\|\Phi\|_{1}=\sum_{\mathrm{i}=1}^{\mathrm{N}}\left|\Phi_{\mathrm{i}}\right|$ denotes the $\boldsymbol{l}_{\mathbf{1}}$ norm, $\|\Phi\|_{\infty}=\underset{1 \leq \mathrm{i} \leq \mathrm{N}}{\max }\left\{\left|\Phi_{\mathrm{i}}\right|\right\}$ represents the $\boldsymbol{l}_{\infty}$ norm $\left(\left|\Phi_{\mathrm{i}}\right|\right.$ denotes the absolute value of $\Phi_{\mathrm{i}}$ ), while $\mathbf{1}$ is a column vector of ones. Furthermore, $\mathrm{c} \geq 1+\frac{1}{\mathrm{~N}}$ denotes the upper bound ${ }^{14}$ of the constraint that involves the $\boldsymbol{l}_{1}$ and $\boldsymbol{l}_{\infty}$ norms. We run the robust estimation strategy using time varying values for $c$. For the first period we set $c=1.1$, but for subsequent periods we set $c$ equal to the value in the range 1.1 to 9.0 that gave the best out-ofsample performance during the previous period, Fan et al. (2008), Fan et al. (2012) and Xing et al. (2014). The conclusions are unaltered when different values of $c$ are used in the first period.

14 The lowest feasible value of $c$ occurs when it is equal to $1+1 / \mathrm{N}$ and all the asset weights are equal to $1 / N$. Simulations of robust portfolio models usually start with a value of $c$ just above 1 . Setting $c$ some way above 1 permits the optimization process to make a trade-off between preventing short sales and allowing large asset weights. 


\section{Black-Litterman approach}

The Black-Litterman portfolio framework combines the subjective views of the investor, in terms of returns and risk, with those of a benchmark portfolio (e.g. the equilibrium market portfolio), and is an alternative way of dealing with estimation risk in the input parameters (Black and Litterman, 1992). The posterior estimates of expected returns and covariances are then used in the portfolio optimization process. We use the portfolio optimization model described in problem (1), which minimizes the portfolio risk (variance), subject to three linear constraints on asset weights.

The column vector of implied excess returns $(\boldsymbol{I})$ for the benchmark portfolio is expressed as follows:

$$
\Pi=\lambda \Sigma \Phi^{\text {benchmark }}
$$

where $\boldsymbol{\lambda}$ denotes the risk aversion coefficient ${ }^{15}$ and $\boldsymbol{\Phi}^{\text {benchmark }}$ is a column vector of the asset weights of the benchmark portfolio ${ }^{16}$. The column vector of the posterior asset returns $\left(\boldsymbol{\mu}_{\mathrm{BL}}\right)$ is given by:

$$
\boldsymbol{\mu}_{\mathrm{BL}}=\left[(\tau \boldsymbol{\Sigma})^{-1}+\mathbf{P}^{\mathrm{T}} \boldsymbol{\Omega}^{-1} \mathbf{P}\right]^{-1}\left[(\tau \boldsymbol{\Sigma})^{-1} \boldsymbol{\Pi}+\mathbf{P}^{\mathrm{T}} \boldsymbol{\Omega}^{-1} \mathbf{Q}\right]
$$

where $\tau$ represents the overall level of confidence in the column vector $\boldsymbol{\Pi}$. We set this parameter to 0.1625 , which is the mean of the values used in the literature (see for instance Platanakis and Sutcliffe, forthcoming).

Bessler, Opfer and Wolff (forthcoming) experimented with different values of the parameter $\tau$, and showed that the Black-Litterman results are robust to the choice of $\tau$ in the range between 0.025 to 1.00. In addition, $\mathbf{P}$ denotes a binary matrix defining the assets involved in each view, $\boldsymbol{Q}$ is a column vector that contains the views (subjective returns), and $\boldsymbol{\Omega}$ is a diagonal matrix that quantifies the reliability of each view. The latter is estimated following Meucci (2010), as follows:

\footnotetext{
15 The investor's risk aversion parameter disappears in the optimization process, since we use just the portfolio variance in the objective function.

16 We have used the equally-weighted portfolio $(1 / N)$ as the benchmark portfolio. Bessler, Opfer and Wolff (forthcoming) show that the effect of the choice of benchmark portfolio on the Black-Litterman results is minimal.
} 


$$
\mathbf{\Omega}=\frac{1}{\delta} \mathbf{P} \Sigma \mathbf{P}^{\mathbf{T}}
$$

where $\delta$ represents the overall level of confidence in the investor's views. We follow Meucci (2010), setting $\delta$ to one. We tried different values of the parameter $\delta$ and found that the impact on the Black-Litterman results is negligible. We follow Bessler, Opfer and Wolff (forthcoming) and use the sample means as subjective return estimates. Following Satchell and Scowcroft (2000) and other studies, we estimate the posterior covariance matrix $\left(\boldsymbol{\Sigma}_{\mathrm{BL}}\right)$ as follows:

$$
\boldsymbol{\Sigma}_{\mathrm{BL}}=\boldsymbol{\Sigma}+\left[(\tau \boldsymbol{\Sigma})^{-1}+\mathbf{P}^{\mathrm{T}} \boldsymbol{\Omega}^{-1} \mathbf{P}\right]^{-1}
$$

Finally, Bessler, Opfer and Wolff (forthcoming) suggest that the reliability of the views incorporated in the Black-Litterman model is time-varying. For each of our out-of-sample periods, we estimate the reliability of the views for the subsequent out-of-sample period using the entire estimation period of 72 months. As a further robustness check, we compared the base case with five versions of the Black-Litterman model where we used the 12, 18, 24, 30 and 36 months immediately prior to the start of each out-of-sample period to estimate the reliability of the views, measured as the variance of the historic forecast errors. For all five of these shorter estimation periods, Black-Litterman remains superior on every performance measure.

\section{Risk-parity portfolio construction}

The risk-parity portfolio approach is based on the idea that portfolio components (i.e. assets) contribute to the same extent to portfolio risk. In its simplified version, the risk-parity approach ignores correlations between asset returns, and the asset weights are anti-proportional to their sample variance. Hence, the portfolio weights are computed as follows:-

$$
\Phi_{\mathrm{i}}=\frac{1 / \sigma_{\mathrm{i}}^{2}}{\sum_{\mathrm{i}=1}^{\mathrm{N}}\left(1 / \sigma_{\mathrm{i}}^{2}\right)}, \quad \forall \mathrm{i}=1, \ldots, \mathrm{N}
$$

\section{Reward-to-risk timing portfolios}

The reward-to-risk timing portfolio strategy has been proposed by Kirby and Ostdiek (2012) and is based on the reward-to-risk ratio, which is defined as the mean return divided by the variance of each asset. Specifically, the reward-to-risk timing strategy takes into account both risk and 
return, and allocates more weight to assets with higher risk-adjusted returns. The portfolio weights are given by:

$$
\Phi_{\mathrm{i}}=\frac{\mu_{\mathrm{i}}^{+} / \sigma_{\mathrm{i}}^{2}}{\sum_{\mathrm{i}=1}^{\mathrm{N}}\left(\mu_{\mathrm{i}}^{+} / \sigma_{\mathrm{i}}^{2}\right)}, \quad \forall \mathrm{i}=1, \ldots, \mathrm{N}
$$

where $\mu_{\mathrm{i}}^{+}=\max \left(\mu_{\mathrm{i}}, 0\right)$ to prevent short selling. In the very rare case when all asset returns are negative, an equally-weighted portfolio $(1 / N)$ is considered. 
Appendix B: Indicators for each CSP dimension

\begin{tabular}{|c|c|c|}
\hline $\begin{array}{l}\text { MSCI KLD } \\
\text { Qualitative Issue } \\
\text { Areas of Interest }\end{array}$ & Strengths & Concerns \\
\hline Community & $\begin{array}{l}\text { - Charitable Giving } \\
\text { - Innovative Giving } \\
\text { - Non-US Charitable Giving } \\
\text { - Support for Housing } \\
\text { - Support for Education } \\
\text { - Indigenous Peoples Relations } \\
\text { - Volunteer Programs } \\
\text { - Other Strength }\end{array}$ & $\begin{array}{l}\text { - Investment Controversies } \\
\text { - Negative Economic Impact } \\
\text { - Indigenous Peoples Relations } \\
\text { - Tax Disputes } \\
\text { - Other Concern }\end{array}$ \\
\hline Diversity & $\begin{array}{l}\text { - CEO's identity } \\
\text { - Promotion } \\
\text { - Board of Directors } \\
\text { - Work/Life Benefits } \\
\text { - Women \& Minority Contracting } \\
\text { - Employment of the Disabled } \\
\text { - Gay \& Lesbian Policies } \\
\text { - Other Strength }\end{array}$ & $\begin{array}{l}\text { - Controversies } \\
\text { - Non-Representation } \\
\text { - Other Concern }\end{array}$ \\
\hline Employee Relations & $\begin{array}{l}\text { - Union Relations } \\
\text { - No-Layoff Policy } \\
\text { - Cash Profit Sharing } \\
\text { - Employee Involvement } \\
\text { - Retirement Benefits Strength } \\
\text { - Health and Safety Strength } \\
\text { - Other Strength }\end{array}$ & $\begin{array}{l}\text { - Union Relations } \\
\text { - Health and Safety Concern } \\
\text { - Workforce Reductions } \\
\text { - Retirement Benefits Concern } \\
\text { - Other Concern }\end{array}$ \\
\hline Environment & $\begin{array}{l}\text { - Beneficial Products and Services } \\
\text { - Pollution Prevention } \\
\text { - Recycling } \\
\text { - Clean Energy } \\
\text { - Communications } \\
\text { - Property, Plant, and Equipment } \\
\text { - Management Systems } \\
\text { - Other Strength }\end{array}$ & $\begin{array}{l}\text { - Hazardous waste } \\
\text { - Regulatory Problems } \\
\text { - Ozone Depleting Chemicals } \\
\text { - Substantial Emissions } \\
\text { - Agricultural Chemicals } \\
\text { - Climate Change } \\
\text { - Other Concern }\end{array}$ \\
\hline $\begin{array}{l}\text { Product Safety \& } \\
\text { Quality }\end{array}$ & $\begin{array}{l}\text { - Quality } \\
\text { - R\&D/Innovation } \\
\text { - Benefits to Economically } \\
\text { Disadvantaged } \\
\text { - Other Strength }\end{array}$ & $\begin{array}{l}\text { - Product Safety } \\
\text { - Marketing/Contracting Concern } \\
\text { - Antitrust } \\
\text { - Other Concern }\end{array}$ \\
\hline
\end{tabular}

